\title{
PPARG: Gene Expression Regulation and Next-Generation Sequencing for Unsolved Issues
}

\author{
Valerio Costa, ${ }^{1}$ Maria Assunta Gallo, ${ }^{2}$ Francesca Letizia, ${ }^{1}$ Marianna Aprile, ${ }^{1}$ \\ Amelia Casamassimi, ${ }^{1,3}$ and Alfredo Ciccodicola ${ }^{1}$ \\ ${ }^{1}$ Institute of Genetics and Biophysics "Adriano Buzzati-Traverso" (IGB), CNR, 80131 Naples, Italy \\ 2 "Centro Diagnostico San Ciro" (CDS), 80055 Portici (NA), Italy \\ ${ }^{3}$ Department of General Pathology, 1st School of Medicine, Second University of Naples, 80138 Naples, Italy
}

Correspondence should be addressed to Alfredo Ciccodicola, ciccodic@igb.cnr.it

Received 10 May 2010; Accepted 8 July 2010

Academic Editor: Chih-Hao Lee

Copyright (c) 2010 Valerio Costa et al. This is an open access article distributed under the Creative Commons Attribution License, which permits unrestricted use, distribution, and reproduction in any medium, provided the original work is properly cited.

\begin{abstract}
Peroxisome proliferator-activated receptor gamma $(\operatorname{PPAR} \gamma)$ is one of the most extensively studied ligand-inducible transcription factors (TFs), able to modulate its transcriptional activity through conformational changes. It is of particular interest because of its pleiotropic functions: it plays a crucial role in the expression of key genes involved in adipogenesis, lipid and glucid metabolism, atherosclerosis, inflammation, and cancer. Its protein isoforms, the wide number of PPAR $\gamma$ target genes, ligands, and coregulators contribute to determine the complexity of its function. In addition, the presence of genetic variants is likely to affect expression levels of target genes although the impact of PPARG gene variations on the expression of target genes is not fully understood. The introduction of massively parallel sequencing platforms — in the Next Generation Sequencing (NGS) era—has revolutionized the way of investigating the genetic causes of inherited diseases. In this context, DNA-Seq for identifying-within both coding and regulatory regions of PPARG gene-novel nucleotide variations and haplotypes associated to human diseases, ChIP-Seq for defining a PPAR $\gamma$ binding map, and RNA-Seq for unraveling the wide and intricate gene pathways regulated by PPARG, represent incredible steps toward the understanding of PPAR $\gamma$ in health and disease.
\end{abstract}

\section{Introduction}

Gene transcription requires an elaborate network of intraand extracellular signals, such as hormones, xenobiotics, micro- and macronutrients (lipid metabolites, vitamins, ions, etc.) and drugs, that converge to the nucleus following different pathways, resulting in the expression of each gene in each tissue. It is a current assumption that transcription is mostly shaped by environmental factors, acting both via direct and indirect mechanisms. Translating exogenous and endogenous signals which affect gene transcription, into a cellular physiological response requires the coordinated action and the fine tuning of transcription factors (TFs) acting at DNA level, including those belonging to the nuclear receptor (NR) superfamily $[1,2]$.

The human NR superfamily comprises 48 ligandinducible transcription factors that respond to a variety of stimuli and are able to modulate their transcriptional activity through conformational changes [3]. The most extensively studied members of this TF superfamily are the Peroxisome proliferator-activated receptors (PPARs, also known as nuclear receptor family 1C, NR1C). Crystallographic studies have shown that all NRs superfamily members, and among them PPARs, share common structural features which include a poorly conserved $\mathrm{N}$-terminal $\mathrm{A} / \mathrm{B}$ domain (with a potential transactivation domain AF-1), a highly conserved DNA binding domain (DBD), with two zinc finger motifs, a C-terminal region containing the ligandbinding domain (LBD) and confer the ligand-dependent transactivation function (AF-2), and a length-variable hinge region between the DBD and LBD [4].

PPARs function as heterodimers with retinoid $\mathrm{X}$ receptor (RXR, NR2B), and their TF activity is regulated by the binding of ligands, the interactions with coregulators (both activator and repressor proteins), and DNA-binding sites [5]. 
In a basal state, the PPARs-RXR complex is bound to corepressors and is transcriptionally inactive. The binding of endogenous or synthetic ligands to the AF-2 domain promotes a conformational change, which results in the release of corepressors, allowing the recruitment of-and the interaction with-coactivators [6]. These proteins either possess or recruit proteins with, histone acetyltransferase (HAT) activity allowing the RNA polymerase II complex to bind and initiate transcription of target genes [4, 7].

PPAR genes are expressed in different organs, such as reproductive and major insulin target organs-liver, white and brown adipose tissue (WAT and BAT, resp.), and skeletal muscle-cardiac tissue, and others [8]. They have been implicated in different biological pathways ranging from lipid and glucose homeostasis and insulin sensitization, to control of cell proliferation/differentiation, tissue injury and wound repair, inflammation, and immunity [9].

PPARs occur in three different isotypes, termed $\alpha$ (NR1C1), $\beta / \delta$ (NR1C2), and $\gamma$ (NR1C3), encoded by three separate genes, localized on human chromosome 22q12q13.1 [10], 6p21.2-p21.1 [11], and 3p25.2 [12], respectively, and expressed in a tissue-specific manner. All three isotypes are able to bind, with different affinities, the same consensus response element on DNA, named peroxisome proliferator response element (PPRE) [13]. Despite their substantial homology and evidence of shared transcriptional targets, the physiological functions of each PPAR are unique.

PPAR $\gamma$, the best studied member of the PPAR family, is induced during the differentiation of preadipocytes into adipocytes and is expressed most abundantly in WAT and BAT [14]. PPARs have a great relevance in the human physiology, but they are also involved in the etiology of many human diseases, and, in this contest, PPAR $\gamma$ is of particular interest because of its pleiotropic functions: it plays a dominant role in the control of the expression of a plethora of genes related to a wide spectrum of physiological processes, such as adipose cell differentiation, metabolism, atherosclerosis, inflammation, and cancer.

Alternative promoters usage and mRNA splicing give rise to at least seven PPAR $y$ isoforms: the $5^{\prime}$ end of the mRNA consists of alternately spliced exons A1, A2, B, C, and $\mathrm{D}$ in various combinations. Each splice variant differs only in the 5'-UTR: the exons at the $5^{\prime}$ end account for little or none of the final translated $\operatorname{PPAR} \gamma$ protein $[15,16]$. In particular, the well-studied PPAR $\gamma 1$ and PPAR $\gamma 2$ have distinct N-terminal portions, differing by the presence of extra 28 (mouse) -30 (human) amino acids for PPAR 2 isoform $[17,18]$. PPAR $\gamma 1$, whose expression can be regulated by multiple promoters $(\gamma 1, \gamma 3$, and $\gamma 4)$, is expressed in all PPAR $\gamma$-expressing tissues and cells whereas PPAR $\gamma 2$ is almost exclusively found in adipose tissue $[19,20]$, where it exerts a pronounced adipogenic activity.

Two PPARG gene $3^{\prime}$ splice variants-lacking almost the entire LBD - $\gamma \mathrm{ORF} 4$ and PPAR $\gamma 1_{\mathrm{tr}}$, have been identified as dominant negative versus PPAR $\gamma$ wild type [21, 22]; hence they are not able to promote the transactivation of PPARG target genes.

The significant number of PPAR $\gamma$ isoforms, as well as for other NRs, strongly suggests that splicing plays an important role in the nuclear receptor functioning. Moreover, the large number of PPAR $\gamma$ target genes, ligands, and coregulators (both coactivators and corepressors) confers additional complexity to PPAR $\gamma$ function. In addition, alterations in the PPAR $\gamma$ trans-activating ability have to be analyzed in the light of environmental factors, genetic background, and the interactions among them [23].

This paper summarizes the transcriptional regulation exerted by PPAR $\gamma$ on key target genes and the effects of the most frequent PPARG gene nucleotide variations on its function, also approaching to the next generation sequencing (NGS) technologies that will allow an unprecedented level of accuracy and completeness to the study of PPAR $\gamma$ and other transcription factors. Indeed, this paper describes in detail how these novel technologies will allow to identify novel genetic variants and polymorphisms (SNPs) in PPARG gene, to draw high-resolution binding map of PPAR $\gamma$ across the genome, and to understand the transcriptional regulation of $\operatorname{PPAR} \gamma$-modulated genes.

\section{PPARG and Gene Expression Regulation (Target Genes)}

PPARy controls several arrays of biological processes by modulating the expression of specific target genes mainly through a ligand-dependent mechanism [24]. PPAR $\gamma$ ligands include a surprisingly diverse set of natural ligands [25] such as prostaglandin PGJ2, linolenic, eicosapentaenoic, docosahexaenoic, and arachidonic acids, and synthetic ligands, such as the thiazolidinediones (TZDs), L-tyrosine-based compounds, several nonsteroidal anti-inflammatory drugs, and a variety of new chemical classes.

The PPARs, and PPAR $\gamma$ among these, like many nonsteroid members of the NR family, function as obligate heterodimers with RXRs [26]. The heterodimers are able to bind PPRE, consisting of direct repeats of the canonical AGGTCA half-site separated by one base pair (DR1) together with the upstream specificity element AAACT [13, 27]. Typically, RXRs do not function alone but rather serve as master regulators of several crucial regulatory pathways, in combination to different NRs' partners.

Recently this issue has been better elucidated through the use of standard chromatin immunoprecipitation (ChIP) coupled with massive sequencing on NGS platform (described more in detail in Section 4.2 entitled "Transcription Factors and ChIP-Seq") [28]. In this study the authors profiled PPAR $\gamma$ - and RXR-binding sites throughout adipogenic differentiation (Figure 1). They identified differential spatial and temporal recruitment of PPARs and RXR to target sites during adipogenesis; in particular, at the onset of differentiation the DNA occupancy by RXR alone was detected. Interestingly, immediately afterwards, many of these sites become occupied by RXR and $\operatorname{PPAR} \delta$, lowly expressed into adipocytes. Moreover, through the early days of differentiation, they observed a different temporal and compositional pattern of occupancy with a switch between PPAR $\delta$ and PPAR $\gamma$, which becomes the main RXR partner throughout the adipogenesis, coinciding with a significant increase in 


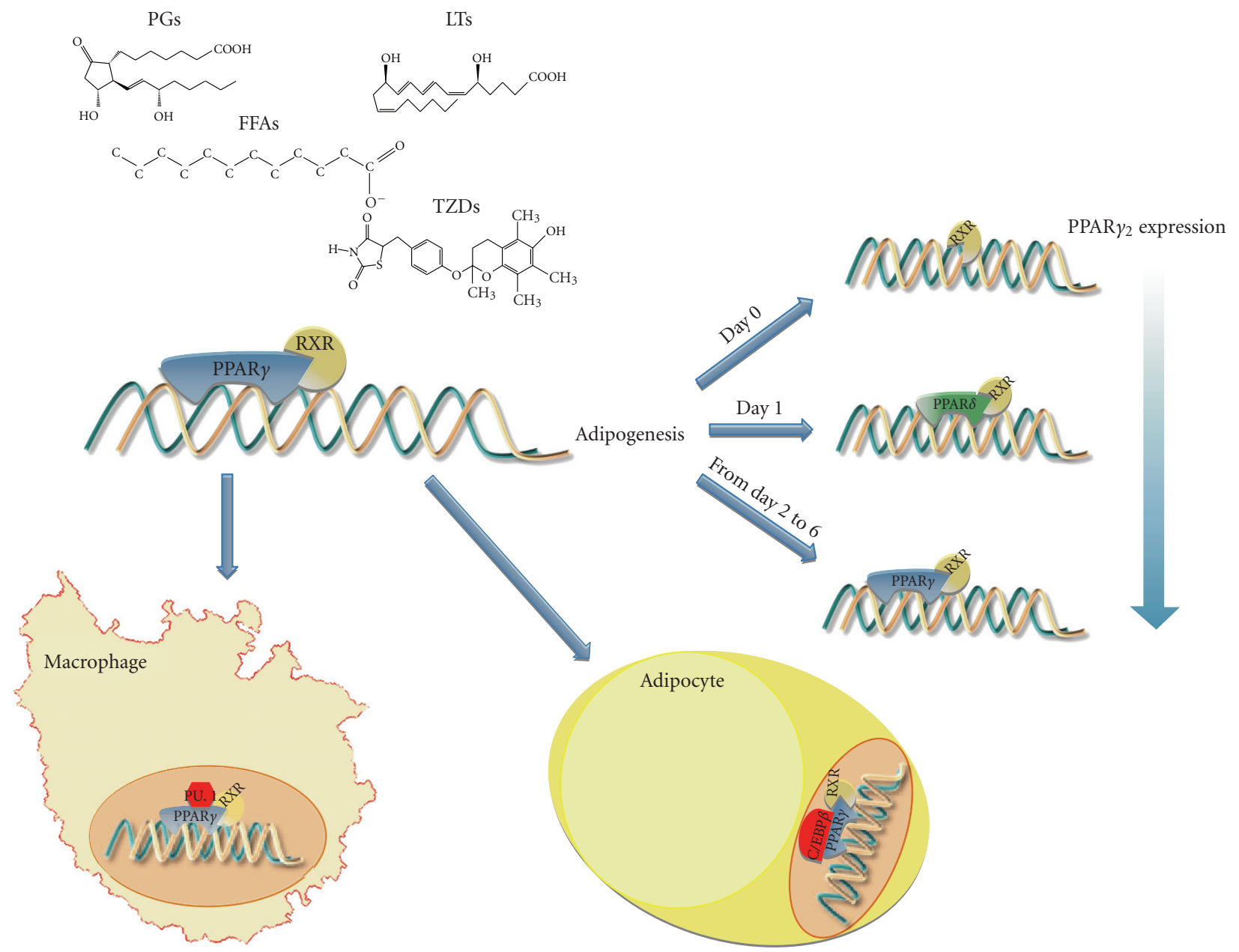

FIGURE 1: Novel insight into PPARG world trough new approaches. In the presence of ligands (upper), PPAR $y$ binds to its PPRE as heterodimer with RXR to activate or repress target genes' expression. The figure summarizes novel molecular mechanisms of PPAR $\gamma$ obtained through ChIP-seq. PPAR $\gamma$ - and RXR-binding sites detected by ChIP-seq reveal different spatial and temporal activation of distinct metabolic pathways and changes in RXR dimer composition during adipogenesis (right panel, study from [28]). PPAR in Adipocytes and Macrophages: tissue-specific regulatory regions employ cell-type-specific coregulators, C/EBP $\beta$ in adipocytes and PU.1 in macrophages (lower panel; ChIPSeq study from [31]).

both PPAR $\gamma 1$ and PPAR $\gamma 2$ expression [28-30]. The binding of RXR alone-in the early stage of differentiation-on the target sites later bound by PPAR $\gamma:$ RXR complex has been hypothesized to serve as a signature needed for subsequent PPAR $\gamma$-dependent binding and/or activation of transcription for target genes [28].

The modulation of transcription depends on the recruitment of cofactors able to remodel the chromatin structure making it more accessible to the basal transcription machinery recruitment and assembly at the core promoter of target genes $[32,33]$. Indeed, it has been widely assumed that chromatin accessibility to the transcriptional machinery, through histone modifications (acetylation, methylation, phosphorylation, ubiquitylation, sumoylation, deimination, ADP ribosylation, and proline isomerization) represents, a very relevant process into gene expression regulation [3437]. In light of this, the different temporal-and compositional pattern - of occupancy on these binding sites, observed by Nielsen and colleagues (2008) [28] is likely to be required for the chromatin remodeling to such loci, rendering these regions accessible for PPAR $\gamma$ :RXR binding and the subsequent transactivation of target genes.

Although PPAR $\gamma$ :RXR heterodimer controls the expression of many inducible genes, transcription is regulated both globally and locally by different factors. Determining which cell-specific coactivators/corepressors are recruited by PPAR $y$ in different cell types, and how these may contribute to chromatin modifications and differential gene expression, represents a crucial issue for fulfilling our gap towards the understanding of PPAR $\gamma$ biology and function.

The currently assumed dogma, mostly referred to all TFs, is that the cell-type-specific trans-activating ability is due to the cooperative binding to other cell-type-selective factors, which specifically "drive" the TF to its target genes.

However, although it is well known that PPAR $\gamma$ is able to modulate target genes' expression in some cell types but 
not others, the molecular mechanisms underlying its ability are not yet well elucidated. Differential binding of PPAR $\gamma$ to the PPRE of target genes or its differential activity at DNA level (i.e., in chromatin remodelling) has been claimed as the putative mechanisms accounting for the cell-type specificity of its action [38].

A very recently published work of Lefterova and colleagues (2010) [31] has provided novel intriguing insight into the molecular basis of cell-type-specific gene expression in primary mouse adipocytes and macrophages. The authors, by using ChIP-Seq (see Section 4.2), identified the molecular signatures of PPAR $\gamma$ binding, disclosing distinct macrophage- and adipose-specific PPAR $\gamma$-binding sites overall the genome. Moreover, they shed light on the cellspecific expression of PPAR $\gamma$ target genes, demonstrating the tight and well-regulated cooperation of PPAR $\gamma$ and other crucial cell-type-specific proteins (PU.1 and C/EBPb, nearby macrophage- and adipocyte-specific target genes, resp.) (see Figure 1). "PPAR $\gamma$ dances with different partners" [38], and all the biological processes $\operatorname{PPAR} \gamma$-modulated can be thus attributed to a differential recruitment of coactivators and corepressors functioning as scaffolds for chromatin remodelling enzymes.

The coactivators of PPAR $y$ include well-established cofactors such as p300/CBP, p160, and PGC-1 (PPAR $\gamma$ coactivator-1), as well as TRAP220 (thyroid hormone receptor-associated protein 220 or PBP, PPAR $\gamma$-binding protein) [39, 40], ARA70 (Androgen Receptor-Associated protein) [41], and PRIP (PPAR $\gamma$-interacting protein, ASC2/RAP250 /TRBP/NRC) [42].

In the absence of ligand, PPAR $\gamma$ recruits corepressors such as silencing mediator for retinoic and thyroid hormone receptors (SMRT) and the nuclear receptor corepressor (N-Cor), which bind repressive enzymes such as histone deacetylase enzymes (HDAC), and particularly HDAC3 [43] or the histone methyl transferase (HMT) SUV39H1, which specifically methylates histone $\mathrm{H} 3$ at lysine 9 (H3K9) [44]. RIP140 (receptor-interacting protein) may also be a component in the corepressor complex $[45,46]$. The ability of PPAR $y$ to repress transcriptional responses to diverse signaling pathways is an essential aspect of its biological activities, but mechanisms determining the specificity and functional consequences of the process known as transrepression remain poorly understood. However, PPAR $\gamma$ can also influence gene expression independently of its binding to the PPRE. Indeed, PPAR $\gamma$-dependent repression of inflammatory gene expression occurs through interference with the action of NF-kB via transrepression [47]. Moreover, the activity of other transcription factors, for example, AP-1 and STAT-1, can be inhibited by PPAR $\gamma$ via direct interaction or by competition for limiting supplies of coactivators [48].

$\operatorname{PPAR} \gamma$ transactivation ability is induced by liganddependent and independent mechanisms. The AF-1 domain of PPAR $\gamma$ is the ligand-independent activation domain that regulates the specificity of PPAR $\gamma$ transcriptional activity during adipogenesis [49]. The presence of an extra 30 aminoacids in the AF- 1 domain of PPAR $\gamma 2$ isoform that makes it a better transcriptional activator than $\operatorname{PPAR} \gamma 1$ [50]. Indeed, it was shown that PPAR $\gamma 2$ is about 10 times more active than PPAR $\gamma 1$ in ligand-independent transcriptional activation, through this domain $[50,51]$. Thus, PPAR $\gamma 1$ and PPAR $\gamma 2$ may have different functions, with PPAR $\gamma 1$ being used when the ligand is abundant whereas PPAR $\gamma 2$ would be crucial under conditions of low ligand concentration, such as it might occur in early adipocyte differentiation [51]. However, the ligand-independent transactivation through the AF-1 domain, common to PPARs, is poorly understood and beyond the scope of this paper.

\subsection{PPARG-Modulated Pathways: Obesity and Inflammation.} The biological activities of PPAR $\gamma$ are very wide but it is generally acknowledged as a transcriptional regulator of lipid and glucose metabolism, since it is highly expressed in adipocytes and controls the expression of several adipocytespecific genes involved in lipid synthesis and storage, insulin signalling, and adipokine production $[52,53]$.

PPAR $\gamma^{-1-}$ mice models, with selective ko in three metabolic tissues (adipose tissue, skeletal muscle, and liver), have revealed that PPAR $\gamma$ is a master regulator of adipogenesis; PPAR $\gamma$ deficiency and/or partial disruption in any of these tissue severely affects whole body lipid homeostasis, altering insulin sensitivity. The essential role of PPAR $\gamma$ in adipogenesis was revealed by inactivation of both PPAR $\gamma 1$ and PPAR $\gamma 2$ in the adipose tissue $[54,55]$.

PPAR $\gamma 2$ depletion was shown to dramatically diminish adipose tissue (WAT) mass_-due to a strongly reduced adipocyte differentiation observed also in vitro-providing protection against high-fat-diet induced weight gain and to determine an impairment of insulin sensitivity [56]. In this context, a common aminoacid polymorphism (Pro12Ala) in PPAR 22 (described in detail in the next section) has been associated with type 2 diabetes and has been suggested to induce a modest impairment of transcriptional activation due to decreased DNA-binding affinity [57].

Conflicting results have been reported by Medina-Gomez and colleagues (2005) [58]. Although they observed a clear in vitro defect in fat cell differentiation, they demonstrated that PPAR $\gamma 2$-depletion is directly linked to insulin resistance, without alteration of in vivo adiposity, even in presence of a high-fat diet. The possible explanation of a residual presence of fat depots in these ko mice strongly suggested that PPAR $\gamma 1$ was able to initiate, at least in part, adipocyte differentiation. In addition, it has been shown a global deregulation in the repartitioning of lipids in these mice models. A complex cross-talk between these metabolically active tissues (liver, adipose tissue, and muscle) appears to be essential for energy balance.

Other studies have demonstrated that mouse models of heterozygous PPAR $\gamma\left(\operatorname{PPAR} \gamma^{-/+}\right)$, with a decreased PPARG gene expression, show improved insulin sensitivity compared to wt mice $[59,60]$ although the reduced PPARG gene expression was associated with decreased metabolic rate and physical activity [61]. Reduction of PPARG gene expression in the PPARG ${ }^{-/+}$mouse model is associated with a mild decrease in PPAR $\gamma$ protein levels [62], suggesting that modulation of PPAR $\gamma$ protein levels, rather than mRNA itself, may play a role in determining PPAR $\gamma$ activity in adipocytes. Indeed, regulation of PPAR $\gamma$ protein translation 
is expected to be tightly regulated. Althoguh a moderate decrease of PPAR $\gamma$ protein may protect against high-fat dietinduced insulin resistance, its complete lack in adipocytes is deleterious to lipid and glucose metabolism as well as insulin sensitivity in the presence of a high fat diet, as shown in most, but not all, studies of adipose-specific PPAR $\gamma$ knockout mouse models [63].

A considerable role for PPAR $y$ in macrophage lipid metabolism has been also clearly demonstrated [64]. The involvement of PPAR $\gamma$ in regulating lipid metabolism in macrophages was initially suggested by the discovery of CD36, member of scavenger receptor family that mediates uptake of oxidized LDL, as a PPAR $\gamma$ target gene in macrophages [65].

PPAR $y$ has a similar function in macrophages and adipocytes as it modulates lipid homeostasis in both cell types via regulation of genes including $L P L$ (lipoprotein lipase), ACAT (acetyl coenzyme A acetyltransferase) and PLA (phospholipase A) genes, and the levels of FFAs (free fatty acids), $P G s$ (prostaglandins), and $L T s$ (leukotriens). PPAR $\gamma$ deficient mice have provided clues to an antiatherogenic role of PPAR $y$ since these mice showed a significantly impaired lipid homeostasis in the arterial wall and enhanced atherosclerosis development $[66,67]$. The molecular mechanisms underlying the antiatherogenic properties of PPAR $y$ involve stimulation of cholesterol efflux from macrophages into the plasma and inhibition of monocyte recruitment into the developing atherosclerotic lesion [67]. Interestingly, macrophage-specific ablation of PPAR $\gamma$ resulted in high rates of insulin resistance suggesting that macrophage $\operatorname{PAAR} \gamma$ may exert a protective role in obesity [68].

Indeed, it is becoming always more evident a functional link between macrophage activity, inflammation, adipose tissue, and type 2 diabetes mellitus (T2DM) [69, 70].

In a physiological state, macrophages residing in fat mass are responsible for keeping in the adipose tissue an antiinflammatory environment, conferring an adequate degree of insulin sensitivity. In pathological conditions, such as obesity, adipose tissue is continually under metabolic stress, leading to the constitutive activation of stress and inflammatory pathways, resulting in macrophage accumulation within the adipose tissue. Proinflammatory macrophages infiltrate adipose tissue, exacerbating local inflammation and giving rise to insulin resistance [31]. In this scenario, even though PPAR $y$ is not required for macrophage differentiation or phagocytic activity, its deficiency is associated with the constitutive onset of an inflammatory milieu, in turn resulting in an enhanced susceptibility to diet-induced obesity, glucose intolerance, and insulin resistance [31].

All these findings indicate the crucial role of PPAR $y$ in adipocytes as well as macrophages, although, to date, only two studies $[28,31]$ have analyzed in-depth the localizations and mechanism of PPAR $y$ recruitment within this cells, trying to address these quite complicated but fundamental questions.

The recent technological advances—such as highthroughput sequencing methods and innovative techniques for following the three-dimensional interactions of chromosomes in the nucleus-allow to rapidly uncover new layers of complexity within PPAR $y$ world. By using these approaches, it would be of interest to analyze the selective pattern of PPAR $\gamma$ activity within specific cell types, with the final aim to understand how its alterations may affect human health.

Several studies have been performed about PPARG gene and its main isoforms, namely, PPAR $\gamma 1$ and $-\gamma 2$, even though other variants have been disclosed [16, 21, 22]. In the near future it would be of great relevance to address also the role of newly described isoforms in physiologic as well as pathologic conditions.

However, the phenotypic effects described for human PPAR $y$ variants, and various mouse models with altered expression of PPARG mRNA, and often conflicting results from different studies so far performed, unequivocally depict a highly complex picture of PPAR $\gamma$ functions and biology.

\section{PPARG Target Genes: Polymorphisms, Haplotypes, and Gene Expression}

$P P A R G$ gene nucleotide variations, and their possible phenotype consequences, have been widely and conversely analyzed in the last two decades $[7,23,71,72]$. Since PPAR $\gamma$ is a transcriptional factor involved in the regulation of several target genes in many tissues, the primary consequence of a genetic variant is likely to be an alteration of expression levels of target genes.

Although the impact of common single nucleotide polymorphisms (SNPs) in PPARG gene on the expression of its target genes is not fully understood, an SNP and/or a combination of them (haplotype) may affect the PPARG transcript itself and in turn its ability to regulate gene expression [23].

What does really happen to PPAR $\gamma$ activity in the presence of a DNA polymorphism and/or mutation? Few studies have directly considered the real effect of PPARG variants on the PPARG expression itself and of its target genes, evaluating the alteration of its binding affinity to PPRE, the promoter efficiency, and other factors that may affect its transactivation ability [73-84].

Indeed, most of the studies about nucleotide variations in PPARG have mainly focused on the association between a DNA variant and a specific phenotype (such as predictors of diabetes, obesity, and BMI) [57, 85-89] or related biochemical markers (plasma levels of hormones, peptides, or metabolites) demonstrated-or just supposed-to be transcriptionally regulated by PPAR $\gamma$ itself $[78,90-102]$.

The most widely studied SNP in PPARG gene [57, 72, 73, 83], Pro12Ala, occurs in PPAR $\gamma 2$ isoform and has been very often associated to clinical consequences and several alterations of physiological metabolic status $[57,72,73,85-$ 87, 89, 103]. About the direct effect of this polymorphism on PPARy activity, some functional studies have revealed that Pro12Ala confers to PPAR $\gamma 2$ a decreased binding affinity to PPRE and a reduced transactivation ability, both in a luciferase reporter gene assay and in TZD-induced adipogenesis $[73,75]$.

It has been also shown that in human adipose tissue there were no significant differences in the basal expression levels 
of some PPAR $\gamma$ target genes (UCP-2, LPL, p85aPI3K, and PPAR 1) between obese Pro12Ala and Pro12Pro carriers, except for a reduction of about $40 \%$ observed for $p 85 a P I 3 K$ gene in the omental fat [78].

To explain the observed discrepancies, between in vitro and in vivo studies, Kolehmainen et al. speculated that subjects Ala12 homozygous have more relevant differences in gene expression activation compared to Ala12 heterozygous; moreover, it must be considered the interaction of genetic and environmental factors and observed tendency for a higher expression of PPAR $\gamma 2$ in the subcutaneous fat depots of Pro12Ala carriers [78].

In addition, Heikkinen and colleagues (2009) [83] have recently highlighted the importance of metabolic context in modulating Pro12Ala effects, reporting or confirming several associations between this PPARG variant and phenotype traits (Table 1). They have shown that in WAT of Ala/Ala mice some genes were downregulated, whereas a great number of genes were upregulated in muscle. Furthermore, they have interestingly suggested that Pro12Ala might be implicated in $G$ protein function, in sensitization of adiponectin signaling and altered cofactors recruitment [83].

To investigate how Pro12Ala might influence gene expression of molecular targets and in turn the response to exogenous stimuli, the functional properties of N-terminal domain should be also considered. In particular, this SNP occurs at position 12 in the N-terminal region of PPAR $\gamma 2$ and shows different transactivation ability than PPAR $\gamma 1$, differing only in its N-terminus. As mentioned above, the additional residues at $\mathrm{N}$-terminus of PPAR $\gamma 2$, encoded by the exon $\mathrm{B}$, confer a trans-activating ability up to tenfold greater than $\operatorname{PPAR} \gamma 1$, indicating that $\gamma 2$ isoform is more potent to induce the expression of target genes in the absence of activating ligands [50]. Pro to Ala amino acid change might affect the secondary structure of the protein and consequently its functionality [110]. Indeed, it has been recently shown that proline residues, although counteracting $\alpha$-helix formation, fit well only into $\mathrm{N}$-terminal of $\alpha$-helices, positively modulating the proteins' stability [111].

The direct relationship between PPAR $\gamma$ transcriptional ability and an SNP in the regulatory region of PPARG gene, C-2821T, was reported by Muller and colleagues (2003) [79] in the Pima Indians population. This polymorphism, in strong linkage disequilibrium (LD) with Pro12Ala, falls within a putative E2-box in a binding site for $\delta E F 1$, a transcriptional repressor. Since it has been shown that C2821T confers to PPAR $\gamma$ an increased transcriptional ability [79], this SNP might be responsible for a decreased binding affinity between $\delta \mathrm{EF} 1$ and E2-box or for a reduced complex stability. Although the mechanism by which these alleles in LD (-2821T and Ala12) function remains uncertain, taken together these findings suggest that Ala12 may alter PPAR $\gamma 2$ transactivation ability, and $-2821 \mathrm{~T}$ may alter transcription of PPAR $\gamma 2$ isoform [79]. Other nucleotide variations, most of them gain- or loss-of-function mutations, have been described in PPARG gene.

A functional study about a rare gain-of-function PPAR $\gamma 2$ mutation, Pro115Gln, highlighted the relevance of phosphorylation at Ser 114 in reducing PPAR $\gamma$ activity; this variation in the ligand independent activation domain of PPAR $\gamma$ affects phosphorylation and renders PPAR $\gamma$ constitutively active, according to increased body mass index (BMI) observed in obese individuals $[71,108]$.

Another PPARG nucleotide variation, affecting PPAR $\gamma$ function, occurs in the same domain: a rare frameshift mutation, [A553 $\triangle$ AAAiT] fs.185[stop186], resulting in a truncated protein in the DBD [76]. Within the same family, this premature stop codon was found in all individuals with insulin resistance and metabolic syndrome (MS), carrying also a similar mutation ([C1984 $\Delta \mathrm{AG}]$ fs.662[stop668]) in PPP1R3A (protein phosphatase1- regulatory subunit 3) [7, $76,82]$. This frameshift is a loss of function mutation that affects heterodimers formation and PPAR $\gamma$ interaction with PPRE in target gene promoters, resulting in a failed transactivation [76].

It has been shown, in vitro, that four rare mutations in the LBD of PPAR $\gamma$ result in a reduced PPAR $\gamma$ trans-activating ability in the presence of a synthetic ligand, affecting its ability to recruit cofactors, ligands, and $\operatorname{RXR} \alpha$ : Pro495Leu (also called Pro467Leu), Val318Met (also called Val290Met), Phe388Leu, and Arg425Cys (Table 1) [7, 71, 74, 77, 81, 109]. The first two mutations affect two helices critical for the recruitment of ligand and cofactors and have dominantnegative activity against wild-type $\operatorname{PPAR} \gamma$. The latter, in contrast, are haploinsufficient mutations, occurring in a hydrophobic region that interacts with $\operatorname{RXR} \alpha$ and ligands $[7,71]$.

In a more recent study, other rare mutations, occurring in DBD-Cys114Arg, Cys131Tyr, and Cys162Trp-and in LBD -315Stop and Arg357X-of PPAR $\gamma$, have been described. These variants encode proteins unable to bind DNA, which lack the transactivation ability and show a dominant negative activity consisting in the competitive recruitment of coactivators with wild-type PPAR $\gamma$ (see Table 1) [82].

Furthermore, we recently reported a novel dominant negative mutation in PPAR $\gamma$ LBD, Ser289Cys, associated with colorectal cancer, dyslipidemia, hypertension, and overweight, but no with T2DM. The formation of an S-S bridge, between Cys289 and Cys285, might impede agonist positioning, explaining the demonstrated reduction of transactivation ability of mutant protein [84].

Although some studies have demonstrated the functional impact of PPARG nucleotide variations on protein activity and/or stability and on its ability to trans-activate target genes, most of PPARG variants have been associated with clinical effects $[71,88,89]$ or plasma levels of a protein without investigating PPARG expression, isoform abundance, and mRNA levels of target genes. These nonfunctional association studies do not prove-allowing just to hypothesize-the altered expression of PPARG target genes. Moreover, it has been demonstrated that gene-gene and gene-environment interactions (i.e., diet, exercise, and age of onset of the disease) may greatly affect the contribution of a specific SNP to the resulting phenotype.

Taken together, these considerations contribute to explain the conflicting results about PPARG nucleotide variations obtained in different populations $[57,73,78,85-$ $89,104,108,110,112-115]$. 
TABLE 1: Nucleotide variations within coding and regulatory regions of PPARG.

\begin{tabular}{|c|c|c|c|}
\hline Variant & Disease/trait & Outcome/Association & References \\
\hline \multirow{9}{*}{ Pro12Ala } & $\begin{array}{l}\mathrm{T} 2 \mathrm{DM} \\
\text { Insulin resistance }\end{array}$ & $\begin{array}{l}\text { Conflicting results about association to T2DM and } \\
\text { insulin resistance. When in LD with C1431T no } \\
\text { protection from T2DM development }\end{array}$ & {$[57,73,83,85,87,89,102,104,105]$} \\
\hline & Cardiac disease & Decreased incidence of cardiac disease & {$[103]$} \\
\hline & HDL & Higher HDL cholesterol & {$[73]$} \\
\hline & BMI & $\begin{array}{l}\text { Reduction of BMI and fat and lean mass in nonobese } \\
\text { (potentiated when in LD with C1431T) and BMI } \\
\text { increase in obese individuals }\end{array}$ & {$[73,83,86,91,106]$} \\
\hline & LPL & Reduced LPL activity and levels. & {$[83,93]$} \\
\hline & Leptin & Increased leptin levels & {$[92,100]$} \\
\hline & Adiponectin & Reduced adiponectin levels & {$[94,96,98,101]$} \\
\hline & Resistin & Reduced resistin levels & {$[97,102]$} \\
\hline & Bone features & $\begin{array}{l}\text { Increase of total bone area and bone mineral content } \\
\text { in Ala/Ala mice. }\end{array}$ & {$[83]$} \\
\hline $\mathrm{C} 1431 \mathrm{~T}$ & $\begin{array}{l}\text { BMI } \\
\text { T2DM } \\
\text { Leptin } \\
\text { Resistin }\end{array}$ & $\begin{array}{l}\text { Increased BMI and fat mass. } \\
\text { Reduced risk of T2DM. } \\
\text { Increased leptin levels. } \\
\text { Increased resistin levels. }\end{array}$ & {$[88,90,91,102,107]$} \\
\hline Pro115Gln & BMI & Increased BMI in obese individuals & {$[108]$} \\
\hline$[\mathrm{A} 553 \Delta \mathrm{AAAiT}]$ & $\begin{array}{l}\text { Insulin resistance T2DM } \\
\text { Hypertension }\end{array}$ & $\begin{array}{l}\text { In association to } 662 \text { stop668 mutation in } P P P 1 R 3 A \\
\text { is responsible of variable hyperinsulinemia, T2DM, } \\
\text { hyperlipidemia, hypertension, and dyslipidemia. }\end{array}$ & {$[76]$} \\
\hline $\begin{array}{l}\text { Pro495Leu and } \\
\text { Val318Met }\end{array}$ & $\begin{array}{l}\text { Insulin resistance } \\
\text { T2DM } \\
\text { Blood pressure } \\
\text { Partial lipodystrophy } \\
\text { Protein plasma levels }\end{array}$ & $\begin{array}{l}\text { Severe insulin resistance, TD2M, and early-onset } \\
\text { hypertension. } \\
\text { Dyslipidemia, preservation of abdominal fat with } \\
\text { selective loss of gluteal and limb subcutaneous fat; } \\
\text { inability to trap and store NEFA in the postprandial } \\
\text { state, hepatic steatosis; reduced adiponectin plasma } \\
\text { levels. }\end{array}$ & {$[74,76]$} \\
\hline Phe388Leu & $\begin{array}{l}\text { Partial lipodystrophy } \\
\text { and related features. }\end{array}$ & $\begin{array}{l}\text { Lipodystrophy and dyslipidemia less severe, with } \\
\text { absence of fat depots on the upper arms, } \\
\text { phlebectasia of limb veins and of hepatic steatosis. } \\
\text { Atherosclerosis, polycystic ovarian disease, increased } \\
\text { C-peptide concentration, higher insulin resistance. }\end{array}$ & {$[77]$} \\
\hline Arg425Cys & $\begin{array}{l}\text { Partial lipodystrophy } \\
\text { T2DM }\end{array}$ & $\begin{array}{l}\text { Diabetes mellitus and hypertriglyceridemia previous } \\
\text { to the development of limb and facial lipoatrophy; } \\
\text { loss of subcutaneous fat, except for sc truncal fat. } \\
\text { Hirsutism in a female carrier. }\end{array}$ & [109] \\
\hline $\begin{array}{l}\text { Cys114Arg } \\
\text { Cys131Tyr } \\
\text { Cys162Trp } \\
\text { 315Stop } \\
\text { Arg357X }\end{array}$ & $\begin{array}{l}\text { Partial lipodystrophy } \\
\text { and related features. }\end{array}$ & $\begin{array}{l}\text { Reduced body fat, partial lipodystrophy of limb and } \\
\text { gluteal depots, insulin resistance, hepatic steatosis, } \\
\text { severe dyslipidemia, increased triglycerides levels, } \\
\text { low HDL levels. } \\
\text { Not for all: early-onset hypertension, cutaneous } \\
\text { eruptive Xanthomata, pancreatitis. }\end{array}$ & {$[82]$} \\
\hline Ser289Cys & Colorectal cancer & $\begin{array}{l}\text { Colonic lesions, reduced restraint of cell } \\
\text { proliferation both in vitro and in vivo, interference } \\
\text { with the inflammatory pathway in tumor tissues and } \\
\text { proximal normal mucosa }\end{array}$ & {$[84]$} \\
\hline A-2819G & $\begin{array}{l}\text { T2DM and diabetic } \\
\text { retinopathy }\end{array}$ & $\begin{array}{l}\text { Association with T2DM and proliferative } \\
\text { retinopathy in diabetic females. }\end{array}$ & {$[88]$} \\
\hline $\begin{array}{l}\text { C-689T } \\
\text { C-681G }\end{array}$ & $\begin{array}{l}\text { BMI } \\
\text { LDL }\end{array}$ & $\begin{array}{l}\text { Increased BMI. } \\
\text { Increased LDL levels. }\end{array}$ & {$[95,99]$} \\
\hline A-14G & $\begin{array}{l}\text { Partial lipodystrophy } \\
\text { MS }\end{array}$ & $\begin{array}{l}-14 \mathrm{G} \text { associated with familial partial lipodystrophy } \\
\text { subtype } 3 \text { (FPLD3). It has been found MS and a } \\
\text { relative reduction of gluteal and extremities'fat. }\end{array}$ & {$[80]$} \\
\hline
\end{tabular}


For instance, Pro12Ala has been often associated with several diseases and phenotype effects [7, 71, 72], such as increased protection from T2DM onset and insulin resistance, decreased incidence of cardiac disease, higher HDL cholesterol, reduction of BMI in nonobese individuals $[57,73,85,87,103]$, and increased BMI in obese individuals $[86,91]$. A recent study in Russian population supports the association of Pro12Ala with improved insulin sensitivity and the protection from T2DM [89]. Moreover, a recent meta-analysis of 60 association studies also confirms the association between Ala12 allele and reduced T2DM risk [110].

In contrast, two recent conflicting studies in the Indian population have shown that Pro12Ala contributes to T2DM development [105] and do not exhibit any association with MS, T2DM, and obesity, respectively [102]. Geneenvironment and gene-gene interactions might strongly contribute to the different Pro12Ala effects observed in the studied populations $[23,116]$.

This SNP has been also associated to altered plasma levels of LPL, leptin, adiponectin, and resistin. Indeed, it was shown, in vivo, that Ala 12 allele is associated with a reduced LPL activity in postheparin plasma [93]; higher leptin levels were observed in Pro12Ala compared to Pro12Pro carrier women [92]. The effect of Pro12Ala on increased leptin levels is likely to be supported by a study in women with functional hyperandrogenism $(\mathrm{FOH})$, in which the authors demonstrated that Ala allele was more frequent in $\mathrm{FOH}$ women than in healthy controls (36\% versus $28 \%$ ) and that leptin levels were higher in nonobese $\mathrm{FOH}$ women compared to controls [100].

Also the association between Pro12Ala and adiponectin plasma levels seems controversial: in the Japanese population Ala12 allele is associated with reduced serum adiponectin levels $[94,96]$ whereas no significant effect of this polymorphism on serum adiponectin was observed in polycystic ovary syndrome, healthy women, and in Asian Indians [98, 101].

In a study by Wang et al. (2004) in [97], it has been reported that Ala12 allele might affect the expression of a gene RETN encoding another adipose tissuerelated molecule, the resistin, in the Chinese population; both heterozygous and homozygous Ala12 carriers showed lower plasma resistin levels compared to homozygous Pro12 carriers [97]. On the opposite, a recent report in an Indian population described no statistically significant differences in resistin plasma levels between Pro12 and Ala12 carriers (both heterozygous and homozygous) [102].

Pro12Ala has been described in linkage disequilibrium (LD) with another common PPARG variant, C1431T; this silent SNP, occurring in the exon 6, is also known as His477His and C161T of exon 6 [71]. It has been observed that when Pro12Ala is in LD with C1431T SNP, its protective effect on T2DM development disappears [87], while the consequences on BMI are potentiated [106].

The lack of functional findings within the abovedescribed association studies and possible influence of ethnicity, environmental and genetic factors are likely to explain the controversial results so far reported. Moreover, due to LD between polymorphisms, determining the relative contribution of each SNP on the resulting phenotype is quite difficult.

For instance, different studies report that $1431 \mathrm{~T}$ allele is associated with an increased BMI in obese Finns [91], a reduced risk of diabetes in a large Asian population [107], and not at all associated with T2DM, obesity, and BMI alteration [88].

About its effects on plasma proteins levels, C1431T has been associated with increased leptin levels [90]. Also Valve et al. [91] observed higher leptin levels in the obese women with C1431T than other obese women studied; this polymorphism was associated with increased fat mass, and, albeit in this study, the authors hypothesize that higher leptin levels were entirely due to increased adipose tissue mass and not directly linked to PPAR $\gamma$-dependent transcriptional regulation [91].

Moreover, also resistin levels were significantly increased in individuals carrying C1431T whereas the Pro-C haplotype was more frequent in groups with lower resistin levels. In contrast, Pro-T and Ala-T haplotypes showed increased frequency in groups with higher resistin levels although statistically not significant [102].

Moreover, nucleotide variations in putative regulatory regions of PPARG have been associated, with different extents, to human diseases. Indeed, we recently identified A2819G SNP in PPARG promoter and observed a significant association with T2DM and proliferative retinopathy in diabetic females whereas no linkage disequilibrium with Pro12Ala nor association with obesity was observed [88]. It has been hypothesized that this SNP might alter PPARG transcript abundance influencing in turn the expression levels of some PPAR $\gamma$ targets involved in the eye physiology [88].

Other three variants in PPARG putative promoter have been identified: A-14G, C-681G, and C-689T [71], even though their impact on PPARG transcription and function has not been completely elucidated. These polymorphisms may possibly affect the expression of some PPAR $\gamma$ molecular targets, since C-681G and C-689T were associated with increased plasma LDL levels and A-14G with a decreased activity of PPAR $\gamma 4$ promoter $[80,95,99]$.

The introduction of massively parallel sequencing platforms, which have offered to researchers the possibility to identify, in a single experiment, point mutations and/or gross genomic rearrangements, within coding and yet unexplored regulatory regions of disease-causing genes, will surely represent a powerful tool to systematically discover variations in PPARG gene, possibly giving a causal link to human diseases.

\section{Next-Generation Sequencing Technologies and Transcription Factors: ChIP-Seq, Targeted Resequencing, and RNA-Seq}

Any genetic information is conveyed from DNA to proteins via mRNA, through a complex and finely regulated process. Unraveling how these genomic information are then translated into gene regulation has been for many decades 
an intriguing field, fulfilled by many advances, speculations, and scientific debate. To achieve this tuned regulation, the concerted action of multiple cis-acting proteins, able to specifically bind cis-regulatory elements, such as promoters and enhancers, is needed [2, 117]. Moreover, since the basal transcriptional activity, resulting from the binding of so-called general TFs to the core promoter, is usually low, different site-specific TFs participate to the recruitment and/or the stabilization of general TFs' complexes, increasing the cell transcriptional rate. Moreover, histone-modifying enzymes may be recruited by other factors-binding to distal enhancer regions-and determine a favourable chromatin environment and a subsequent transcriptional enhancement. On the other hand, the transcription can be negatively modulated through the binding of repressive factors to distal silencer regions or the competition with TFs themselves.

To understand PPAR $\gamma$-mediated phenomena in a specific cell/tissue/organ one cannot ignore the consideration that $\operatorname{PPAR} \gamma$ is a transcription factor. Its mechanistic understanding represents a prerequisite for fine-tuning the therapeutic activities of PPARG.

More generally, several human diseases have been directly linked to alterations in the gene expression caused by defects in the structure and/or function of a key transcriptional regulator [2] although it is arguable that many other "TFdisease associations" still remain to be identified. Expanding our understanding of how site-specific TFs contribute to gene expression regulation, and in turn how alterations in both TF structure and activity may account for a specific disease phenotype, appears to be a crucial endpoint.

In this context, the specific case of PPAR $\gamma$ is not an exception, rather it is likely to be one of the most representative candidate genes in "TF-disease" association studies, for its involvement in many physiological and also pathological processes [7].

To this aim, the introduction of massively parallel sequencing platforms in the 2004, coupled with the recent advances in chromatin immune-precipitation (ChIP) followed by sequencing (ChIP-seq), has clearly revolutionized the way we approach to-and also study-different biological phenomena [118-121]. Although all the sequencing platforms commercially available use different sequencing chemistry and methodological procedures, also varying in the number of sequenced reads, read length and error characteristics, they all are based on the generation of libraries to sequence, and the miniaturization of individual sequencing reactions [121]. Unlike previously used tag-based sequencing methods, such as Serial and Cap Analysis of Gene Expression (SAGE and CAGE, resp.), Polony Multiplex Analysis of Gene Expression (PMAGE), NGS libraries do not require a prior step of cloning before sequencing. Moreover, a common feature of NGS platforms is the template binding to a solid surface or support (immobilization by primer or template) or its indirect immobilization (by linking a polymerase to the support) [122]. However, whatever are the sequencing chemistry and the methodological procedures used, a single NGS platform can generate a large amount of data up to 2 gigabases $(\mathrm{Gb})$ of sequence reads per day, shifting the effort of researchers from biology to bioinformatics.
These platforms have been quickly applied to many scientific contexts, giving rise to many "Seq" protocols, specifically developed and suited for a particular research branch, from transcriptomics (RNA-Seq) to the targeted resequencing for the identification of disease-causing nucleotide variations (CNV-Seq and DNA-Seq), including DNA-protein interaction studies (ChIP-Seq) and genome-wide profiling of epigenetic marks (Methyl-Seq).

Although it is beyond any doubt that NGS platforms have changed the way we think about many scientific issues, one of the broadest and useful applications of this technology is towards the identification of the genetic causes of inherited diseases, both mendelian and multifactorial.

In light of this, deeply investigating $P P A R G$ - from DNA variations to gene expression and its regulation-will surely enhance our understanding about its involvement in health and disease. Identifying novel nucleotide variations, both point mutations and gross genomic rearrangements, within coding regions and yet unexplored intronic and regulatory regions of PPARG by targeted resequencing (on NGS platforms) will be the first brick towards building a more complete and detailed view of PPARG function and activity (summarized in Figure 2). In addition, the possibility to identify the exact position of its binding sites and thus draw a complete high-resolution binding map across the genome (by ChIP-Seq) $[123,124]$, combined with the large amount of useful whole transcriptome data obtained by RNA-seq, will provide an unprecedented level of accuracy and complexity than ever done (see Figure 1) [125].

4.1. NGS for the Targeted Resequencing. The whole genome resequencing of affected individuals' genomes by the use of NGS platforms is likely to represent the most powerful approach to identify single nucleotide variants and/or genomic rearrangements (insertions, deletions, and copy number variations) within disease-causing genes. Nonetheless, it is clear that such genome-wide approach cannot be used for a routine mutational screening in wide number of affected individuals, due to the high computational and economic effort required, particularly considering that there are few research groups in big companies and/or large corporations, as well as big public and private world leading research institutions, able to sustain these costs.

Thus, targeted resequencing of a small number of candidate genes or disease loci appears to be the only reliable way to obtain the high accuracy of NGS data at the accessible costs of a standard array analysis. On the other hand, it appears crucial to have efficient and cost-effective capture methods to enrich the sample with "high-value" genomic regions to sequence in order to avoid off-target sequencing.

In light of this, different techniques have been recently developed allowing researchers to enrich their sample of target genomic regions to be further sequenced. Multiplex PCR amplification of specific target regions was first used for candidate gene approaches, to enrich the samples with regions of interest, further processed to prepare libraries prior to sequencing [126-128]. Another approach is the capture-by-hybridization [129]. Efficient array-based 


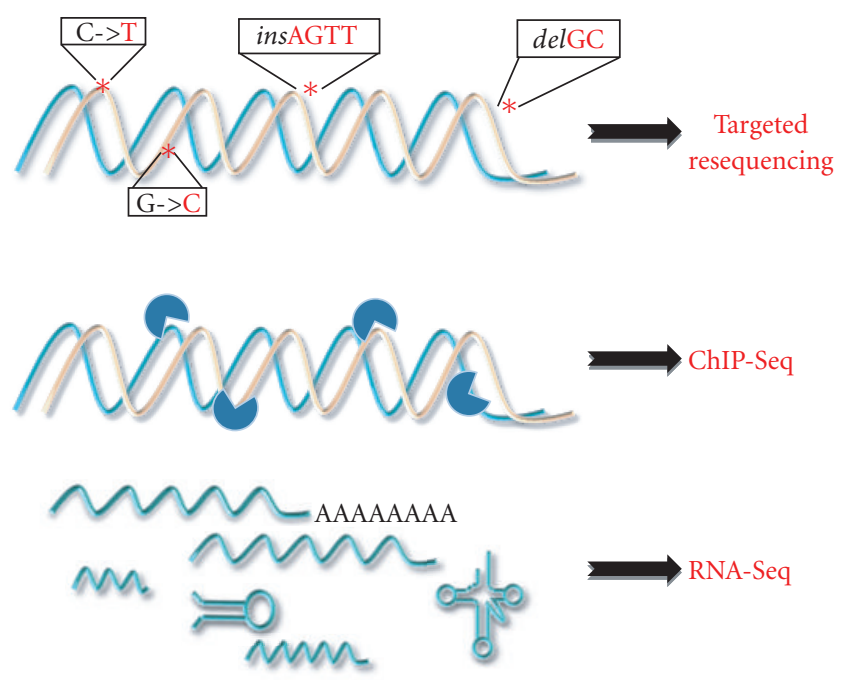

FIGURE 2: Innovative approaches by using next generation sequencing technologies. Next generation sequencing can be applied to many scientific contexts: targeted resequencing for the identification of disease-causing nucleotide variations for both coding and unexplored regulatory regions of genes (CNV-Seq and DNA-Seq); ChIP-Seq, for DNA-protein interaction studies coupling chromatin immunoprecipitation (ChIP) and massively parallel sequencing; RNA-Seq, for whole transcriptome studies, including expression levels of known and yet unknown transcripts (both coding and non-coding), differential splicing, allele-specific expression, RNA editing, and fusion transcripts (see review [121]).

capture approaches (custom in-situ synthesized oligonucleotide microarrays) have been successfully used to enhance the sequencing template enrichment [130-133]. Companies, such as NimbleGen, have recently developed microarrays for the capture-by-hybridization of thousands of predefined genomic regions, mainly coding regions (exons), widely used for targeted resequencing experiments [134]. Several research groups have clearly shown that the above-described capture methods are playing a crucial role in driving targeted resequencing applications of NGS platforms [129].

Since most of human genetics studies have so far mainly focused on protein-coding exons, these regions usually represent high-value targets for targeted resequencing, even though this approach can be-and we believe in most cases it must be-extended to gene regulatory regions (upstream the translation start sites and introns). Indeed, the identification of nucleotide variations in putative or already known regulatory sequences, within non-coding genomic regions, is therefore of great relevance for future research. This approach appears to be very promising above all for the study of TFs binding sites, since their involvement in human disease, both mendelian and multifactorial [135]. Barrio and colleagues (2009) [135] first identified, by target resequencing of a genomic region encompassing about $20 \mathrm{~kb}$, non-coding variations associated with two kinds of red cell aplasia, demonstrating that non-coding RPS19 gene sequence variants contribute to the high clinical variability observed in red cell aplasia. They hypothesized that specific alleles in these non-coding regions may alter the binding of regulatory proteins and/or TFs, possibly altering or removing an important stimulus for hematopoiesis [135].

In this context, the possibility to have high enrichment for the both coding and unexplored regulatory regions of PPARG, coupled to the targeted resequencing on NGS platforms, will represent a very powerful approach for researchers. Indeed, it is likely to allow the identification of all the potential risk-conferring variations, within its coding regions, of putative novel single nucleotide variations (mutations and SNPs) and insertions/deletions or other genomic rearrangements, possibly associated to human diseases. It will also allow gaining further insights into the genomic architecture of its regulatory regions, offering the possibility to rapidly and accurately identify potential sources of variation responsible for the alteration of its mRNA levels. Moreover, the specific enrichment of target regions, followed by targeted resequencing, could also be performed on wellknown PPAR $\gamma$-regulated genes in specific pathways.

Indeed, since several studies performed on PPAR $\gamma$ target genes have not unequivocally shown a clear correlation between SNPs and the related human diseases, by using these approaches it will be easier to identify specific alleles in non-coding regions of target genes and verify whether these nucleotide variations are responsible for the alteration of known PPRE-and in turn of PPAR $y$ binding to these elements_-finding a direct and functional link to the disease.

4.2. Transcription Factors and ChIP-Seq. Thanks to the introduction of NGS platforms, widely used approaches of chromatin immuno-precipitation followed by microarray (ChIPchip) have been flanked - and in many cases substituted-by ChIP-seq protocols. Indeed, in ChIP-seq, the DNA fragments of interest (i.e., binding sites for a TF) are directly sequenced instead of being hybridized on a chip-array. Thanks to the high resolution, coverage, the wider dynamic range, and the absence of hybridization-based artifacts, ChIP-Seq allows now researchers to improve both quantity and quality of produced data. Moreover, fundamental advances toward a 
more accurate definition of the consensus sequences for the binding of TFs have been done [136].

To date, this novel approach, which couples in a single experiment a standard ChIP assay to the large-scale massive sequencing of target genome regions, allows researchers to obtain a more complete map of TFs-DNA interactions [2]. Drawing a precise map of TFs binding sites, core transcriptional machinery, and other DNA-binding proteins is a crucial step towards the identification of gene regulatory networks underlying physiological as well as pathological processes [136].

In particular, since PPAR $\gamma$ acts in combination with RXR as heterodimer and requires the cooperation with many different tissue-selective factors, understanding the differential spatial and temporal recruitment of PPAR $\gamma: \operatorname{RXR}$ complex to target genes is likely to improve our knowledge about PPAR $y$ biology.

In a recent study, Nielsen et al. [28] by ChIP-Seq on NGS platform (Illumina, Roche) obtained a PPAR $\gamma$ - and RXR-binding sites map during the adipocytes differentiation of 3T3-L1 cells [28]. In particular, they sequenced a total of about 86 million of fragments (divided for the six days of the analysis on the adipocytes) derived from PPAR $\gamma$ ChIP assay and about 50 million derived from RXR ChIP. They demonstrated that spatial and temporal recruitment of PPAR $\gamma$ and RXR to target genes varied during adipogenesis (Figure 1). More in detail, they observed that in the very early stages of adipocyte differentiation, coinciding with the very low levels of PPAR $\gamma$ at day 0 , only nine PPAR $\gamma$ target sites were detectable, and however this number remained low at day 1 . In contrast, a high DNA occupancy by RXR alone was detected. More interestingly, going on with the differentiation process, most of these sites become occupied by $\operatorname{PPAR} \delta: R X R$ complexes. A subsequent switch-starting at day 2-between PPAR $\delta$ and PPAR $\gamma$, which becomes the main RXR partner throughout the adipogenesis, coincided with a significant increase in both PPAR $\gamma 1$ and PPAR $\gamma 2$ expression [28-30]. They identified $>5000$ high-confidence PPAR $\gamma:$ RXR-binding sites in adipocytes coinciding to the majority of induced genes. In silico analysis allowed to observe that binding occurs in the proximity of genes involved in lipid and glucose metabolism. The highest number (about 7000) of PPAR $\gamma$ :RXR-binding sites was observed at day 6. This genome-wide ChIP-Seq analysis allowed to confirm the binding of PPAR $\gamma$ :RXR heterodimer to well-established PPREs in already known target genes. In addition, novel target sites in introns of different genes were also identified.

ChIP-Seq was also recently used by Lefterova and colleagues (2010) [31] to address a critical issue affecting several reports about PPAR $\gamma$ function, the specificity of action, that is, how PPAR $\gamma$ modulates target genes in some cell types but not others. By using this innovative approach, the authors determined which cell-type-specific cofactors are recruited by PPAR $\gamma$ in mouse macrophages and adipocytes [31]. Indeed, it has been widely demonstrated the PPAR $\gamma$ transactivation ability on target genes, with characteristic cell-type specific patterns of gene modulation, but the molecular basis of such a specificity has not yet been fully understood.
As generally assumed for other TFs, it has been postulated that its cell-type specificity might be due to a differential binding to consensus sequences in the regulatory regions of target genes or a differential ability to recruit chromatin remodelling enzymes [38]. The authors identified a specific molecular signature of PPAR $\gamma$ binding, by massively sequencing-overall the mouse genome-the regions directly bound by $\operatorname{PPAR} \gamma$. This analysis revealed that PPAR $\gamma$ cooperates with some cell-type-specific factors, PU. 1 and C/EBP $\beta$, in the defining the specificity of action for PPAR $\gamma$ in each cell type (macrophages and adipocytes, resp.) (Figure 1). PPAR $\gamma$ in macrophages binds uniquely at genomic sites located in the proximity of immunity-related genes and specifically colocalizes with PU.1 in areas of open chromatin and in presence of histone acetylation whereas, in preadipocytes, the presence of a repressive histone signature excludes PPAR $y$ from macrophage-specific sites. In this case it has been shown that PPAR $\gamma$ is able to open the chromatin and increase histone acetylation at adipocytespecific genomic sites. This paper demonstrates that, at least in these cell types, the transcriptional regulation exerted by $\operatorname{PPAR} \gamma$ is attributed to a differential recruitment of specific cofactors functioning as scaffolds for chromatin remodelling enzymes.

Above described works have clearly shown the great potential of sequencing-based ChIP assays, which do not require a priori information about the genomic position of TFs binding sites and allow to generate high-resolution binding maps in response to a specific stimulus [123, 124]. However, as demonstrated in a recent work by Reddy and colleagues (2009) [125], coupling ChIP-Seq to RNA-Seq (described in detail in the next paragraph) for studying the response of a TF to a specific drug allows to examine wellknown models at much greater depth and detail. In particular, they obtained a comprehensive map of glucocorticoid receptor binding to DNA overall the genome by ChIP-Seq, and measured related changes in gene expression by RNASeq, in response to treatment with dexamethasone [125].

We firmly believe that combining a sequencing-based ChIP assay to high-throughput transcriptome analysis by RNA-Seq on NGS platforms, above all for inducible transcription factors (and PPAR $\gamma$ among them), will surely provide a complete, accurate, and reliable source of useful of data, enabling to complete, piece by piece, the intricate puzzle of PPAR $\gamma$ functions.

\subsection{Discovering the Transcriptional Landscape through RNA-} Seq. Since the end of the 90s the term "transcriptome" was used to describe the identity of each expressed gene in a specific cell type and/or tissue/organ/organism, and of its related transcriptional levels [137]. It was first believed to consist of $80-90 \%$ of ribosomal RNA (rRNA), $5-15 \%$ of transfer RNA (tRNA), and the remaining fraction of messenger RNA (mRNA), with most of the genome consisting of untranscribed and genetically inert regions.

In contrast, recent evidences have shown that both intragenic and intergenic sequences cannot be any longer considered as "junk DNA", but they represent one of the 
main driving force accounting for diversity and biological complexity of all living organisms [121]. Indeed, several studies have demonstrated an unexpected level of complexity of the eukaryotic transcription, showing its pervasive nature with almost the full length of nonrepeat regions of the genome being transcribed $[138,139]$.

Hence, interpreting the complexity of a whole transcriptome is likely to be a crucial endpoint for unraveling the role of functional elements of a genome, and, in light of this, the introduction of NGS platforms has provided researcher a powerful tool for analysis in a single experiment.

Indeed, the rapid diffusion of RNA-Seq protocols has raised the possibility to quantify the differential expression of transcripts in both physio- and pathological conditions and to identify and characterize all the transcripts (both proteincoding and non-coding) expressed within a specific cell and/or tissue - at a particular development stage or after an endogenous or exogenous stimulus - correctly determining the splicing and the structure of genes. Unlike hybridizationbased gene expression methods (microarray) and tag-based sequencing (i.e., CAGE and SAGE), RNA-Seq does not require prior knowledge of any gene sequence (as occurs for microarrays) or laborious and time-consuming steps for the cloning and sequencing (as occurs for existing tag-based approaches) (reviewed in [121]).

Several recent studies have clearly demonstrated the advantages of using RNA-Seq in the interrogation of transcriptomes under multiple conditions, such as cell proliferation, differentiation, and various environmental stress [140148 .

In this context, due to the crucial role of PPAR $y$ as TF involved in many cellular pathways, investigating the PPAR $\gamma$ dependent regulation of target genes expression via RNA-Seq in a single experiment represents a great challenge.

Whereas previously described ChIP-Seq allows to draw a binding map of PPAR $\gamma$ to PPRE, activating or repressing target gene expression, directly identifying (by RNA-Seq) the gene expression response to PPAR $\gamma$-modulating drugs (agonists such as TZD), or in particular development conditions (during adipogenesis), will provide researchers the opportunity to directly measure its ability to modulate the transcription of specific genes in a cell/tissue specific manner.

Since high-throughput sequencing has definitely proved to be a powerful and quantitative method to sample the transcriptomes at single nucleotide resolution [149], the use of RNA-Seq is likely to shed a new light on the specificity of action of PPAR $\gamma$ in different cell types or tissue, in both physiological and pathological conditions. Several unsolved questions about the "real" impact of PPAR $\gamma$ on the regulation of target gene expression-in several conditions-can now be fruitfully addressed by the use of NGS.

\section{Concluding Remarks}

Over the past years, PPARs, and especially $\operatorname{PPAR} \gamma$, have emerged as crucial transcription factors modulating the expression of genes involved in several important pathways and biological processes and, noteworthy, in human diseases.
Despite the huge knowledge in the field, future research efforts will undoubtedly reveal novel mechanisms through which PPAR $\gamma$ integrates these complex physiological and pathological pathways. Particular attention should be given to the question of how the selective effects of PPAR $y$ are achieved in different cell types. It will also be of great importance to understand the subtle mechanisms dictating this selectivity of action through the study of its different isoforms, genetic variations, and their recruited cofactors able to remodel the chromatin structure. Knowing all the $\operatorname{PPAR} \gamma$ targets is a prerequisite for a full understanding of the metabolic defects that occur in people with PPARG mutations and/or variation and will help in the interpretation of effects - and also side effects - that can occur with PPAR $\gamma$ agonists already in clinical use. Thus, to have a complete picture of PPAR $\gamma$ functions and implications, studying altogether these aspects, through the use of massively parallel sequencing platforms, will provide a way to better characterize the actions of PPARG products and agonists.

\section{Acknowledgments}

V. Costa and M. A. Gallo contributed equally to this work. Department of Biological Sciences, University of Naples Federico II, 80138 Naples, Italy is the present address of the co-author Amelia Casamassimi.

\section{References}

[1] V. Perissi and M. G. Rosenfeld, "Controlling nuclear receptors: the circular logic of cofactor cycles," Nature Reviews Molecular Cell Biology, vol. 6, no. 7, pp. 542-554, 2005.

[2] P. J. Farnham, "Insights from genomic profiling of transcription factors," Nature Reviews Genetics, vol. 10, no. 9, pp. 605616, 2009.

[3] D. J. Mangelsdorf, C. Thummel, M. Beato et al., "The nuclear receptor super-family: the second decade," Cell, vol. 83, no. 6, pp. 835-839, 1995.

[4] J. P. Renaud and D. Moras, "Structural studies on nuclear receptors," Cellular and Molecular Life Sciences, vol. 57, no. 12, pp. 1748-1769, 2000.

[5] J. Berger and D. E. Moller, "The mechanisms of action of PPARs," Annual Review of Medicine, vol. 53, pp. 409-435, 2002.

[6] J. Torchia, C. Glass, and M. G. Rosenfeld, "Co-activators and co-repressors in the integration of transcriptional responses," Current Opinion in Cell Biology, vol. 10, no. 3, pp. 373-383, 1998.

[7] C. Knouff and J. Auwerx, "Peroxisome proliferator-activated receptor- $\gamma$ calls for activation in moderation: lessons from genetics and pharmacology," Endocrine Reviews, vol. 25, no. 6, pp. 899-918, 2004.

[8] O. Braissant, F. Foufelle, C. Scotto, M. Dauça, and W. Wahli, "Differential expression of peroxisome proliferator-activated receptors (PPARs): tissue distribution of PPAR- $\alpha,-\beta$, and $-\gamma$ in the adult rat," Endocrinology, vol. 137, no. 1, pp. 354-366, 1996.

[9] L. Michalik and W. Wahli, "Peroxisome proliferator-activated receptors: three isotypes for a multitude of functions," Current Opinion in Biotechnology, vol. 10, no. 6, pp. 564-570, 1999. 
[10] T. Sher, H.-F. Yi, O. W. McBride, and F. J. Gonzalez, "cDNA cloning, chromosomal mapping, and functional characterization of the human peroxisome proliferator activated receptor," Biochemistry, vol. 32, no. 21, pp. 5598-5604, 1993.

[11] T. Yoshikawa, Z. Brkanac, B. R. Dupont, G.-Q. Xing, R. J. Leach, and S. D. Detera-Wadleigh, "Assignment of the human nuclear hormone receptor, NUC1 (PPARD), to chromosome 6p21.1-p21.2," Genomics, vol. 35, no. 3, pp. 637-638, 1996.

[12] G. A. Francis, E. Fayard, F. Picard, and J. Auwerx, "Nuclear receptors and the control of metabolism," Annual Review of Physiology, vol. 65, pp. 261-311, 2003.

[13] A. IJpenberg, E. Jeannin, W. Wahli, and B. Desvergne, "Polarity and specific sequence requirements of peroxisome proliferator- activated receptor (PPAR)/retinoid X receptor heterodimer binding to DNA. A functional analysis of the malic enzyme gene PPAR response element," Journal of Biological Chemistry, vol. 272, no. 32, pp. 20108-20117, 1997.

[14] E. D. Rosen, P. Sarraf, A. E. Troy et al., "PPAR $\gamma$ is required for the differentiation of adipose tissue in vivo and in vitro," Molecular Cell, vol. 4, no. 4, pp. 611-617, 1999.

[15] J. Zhou, K. M. Wilson, and J. D. Medh, "Genetic analysis of four novel peroxisome proliferator activated receptor- $\gamma$ splice variants in monkey macrophages," Biochemical and Biophysical Research Communications, vol. 293, no. 1, pp. 274-283, 2002.

[16] S. McClelland, R. Shrivastava, and J. D. Medh, "Regulation of translational efficiency by disparate $5^{\prime}$-UTRs of PPAR $\gamma$ splice variants," PPAR Research, vol. 2009, Article ID 193413, 8 pages, 2009.

[17] Y. Zhu, C. Qi, J. R. Korenberg et al., "Structural organization of mouse peroxisome proliferator-activated receptor $\gamma(\operatorname{mPPAR} \gamma)$ gene: alternative promoter use and different splicing yield two mPPAR $y$ isoforms," Proceedings of the National Academy of Sciences of the United States of America, vol. 92, no. 17, pp. 7921-7925, 1995.

[18] L. Fajas, D. Auboeuf, E. Raspé et al., "The organization, promoter analysis, and expression of the human PPAR $\gamma$ gene," Journal of Biological Chemistry, vol. 272, no. 30, pp. 18779-18789, 1997.

[19] P. Tontonoz, E. Hu, and B. M. Spiegelman, "Stimulation of adipogenesis in fibroblasts by PPAR $\gamma 2$, a lipid-activated transcription factor," Cell, vol. 79, no. 7, pp. 1147-1156, 1994.

[20] A. J. Vidal-Puig, R. V. Considine, M. Jimenez-Liñan et al., "Peroxisome proliferator-activated receptor gene expression in human tissues: effects of obesity, weight loss, and regulation by insulin and glucocorticoids," Journal of Clinical Investigation, vol. 99, no. 10, pp. 2416-2422, 1997.

[21] L. Sabatino, A. Casamassimi, G. Peluso et al., "A novel peroxisome proliferator-activated receptor $\gamma$ isoform with dominant negative activity generated by alternative splicing," Journal of Biological Chemistry, vol. 280, no. 28, pp. 2651726525, 2005.

[22] H. J. Kim, I. S. Woo, E. S. Kang et al., "Identification of a truncated alternative splicing variant of human $\operatorname{PPAR} \gamma 1$ that exhibits dominant negative activity," Biochemical and Biophysical Research Communications, vol. 347, no. 3, pp. 698-706, 2006.

[23] V. Costa, A. Casamassimi, and A. Ciccodicola, "Nutritional genomics era: opportunities toward a genome-tailored nutritional regimen," Journal of Nutritional Biochemistry, vol. 21, no. 6, pp. 457-467, 2010.

[24] N. J. McKenna and B. W. O’Malley, "Combinatorial control of gene expression by nuclear receptors and coregulators," Cell, vol. 108, no. 4, pp. 465-474, 2002.
[25] S. A. Kliewer, S. S. Sundseth, S. A. Jones et al., "Fatty acids and eicosanoids regulate gene expression through direct interactions with peroxisome proliferator-activated receptors $\alpha$ and $\gamma$," Proceedings of the National Academy of Sciences of the United States of America, vol. 94, no. 9, pp. 4318-4323, 1997.

[26] A. Chawla, Y. Barak, L. Nagy, D. Liao, P. Tontonoz, and R. M. Evans, "PPAR- $\gamma$ dependent and independent effects on macrophage-gene expression in lipid metabolism and inflammation," Nature Medicine, vol. 7, no. 1, pp. 48-52, 2001.

[27] V. Chandra, P. Huang, Y. Hamuro et al., "Structure of the intact PPAR- $\gamma$-RXR- $\alpha$ nuclear receptor complex on DNA," Nature, vol. 456, no. 7220, pp. 350-356, 2008.

[28] R. Nielsen, T. Å. Pedersen, D. Hagenbeek et al., "Genomewide profiling of PPAR $\gamma:$ RXR and RNA polymerase II occupancy reveals temporal activation of distinct metabolic pathways and changes in RXR dimer composition during adipogenesis," Genes and Development, vol. 22, no. 21, pp. 2953-2967, 2008.

[29] L. Madsen, R. K. Petersen, M. B. Sørensen et al., "Adipocyte differentiation of 3T3-L1 preadipocytes is dependent on lipoxygenase activity during the initial stages of the differentiation process," Biochemical Journal, vol. 375, no. 3, pp. 539-549, 2003.

[30] I. Tzameli, H. Fang, M. Ollero et al., "Regulated production of a peroxisome proliferator-activated receptor- $\gamma$ ligand during an early phase of adipocyte differentiation in 3T3-L1 adipocytes," Journal of Biological Chemistry, vol. 279, no. 34, pp. 36093-36102, 2004.

[31] M. I. Lefterova, D. J. Steger, D. Zhuo et al., "Cell-specific determinants of peroxisome proliferator-activated receptor $\gamma$ function in adipocytes and macrophages," Molecular and Cellular Biology, vol. 30, no. 9, pp. 2078-2089, 2010.

[32] F. J. Dilworth and P. Chambon, "Nuclear receptors coordinate the activities of chromatin remodeling complexes and coactivators to facilitate initiation of transcription," Oncogene, vol. 20, no. 24, pp. 3047-3054, 2001.

[33] L. Ho and G. R. Crabtree, "Chromatin remodelling during development," Nature, vol. 463, no. 7280, pp. 474-484, 2010.

[34] B. D. Strahl and C. D. Allis, "The language of covalent histone modifications," Nature, vol. 403, no. 6765, pp. 41-45, 2000.

[35] Y. Zhang and D. Reinberg, "Transcription regulation by histone methylation: interplay between different covalent modifications of the core histone tails," Genes and Development, vol. 15, no. 18, pp. 2343-2360, 2001.

[36] R. J. Sims III, K. Nishioka, and D. Reinberg, "Histone lysine methylation: a signature for chromatin function," Trends in Genetics, vol. 19, no. 11, pp. 629-639, 2003.

[37] T. Kouzarides, "Chromatin modifications and their function," Cell, vol. 128, no. 4, pp. 693-705, 2007.

[38] E. Scotti and P. Tontonoz, "Peroxisome proliferator-activated receptor $\gamma$ dances with different partners in macrophage and adipocytes," Molecular and Cellular Biology, vol. 30, no. 9, pp. 2076-2077, 2010.

[39] K. Ge, M. Guermah, C.-X. Yuan et al., "Transcription coactivator TRAP220 is required for PPAR $\gamma 2$-stimulated adipogenesis," Nature, vol. 417, no. 6888, pp. 563-567, 2002.

[40] Y. Zhu, C. Qi, S. Jain, M. S. Rao, and J. K. Reddy, "Isolation and characterization of PBP, a protein that interacts with peroxisome proliferator-activated receptor," Journal of Biological Chemistry, vol. 272, no. 41, pp. 25500-25506, 1997.

[41] C. A. Heinlein, H.-J. Ting, S. Yeh, and C. Chang, "Identification of ARA70 as a ligand-enhanced coactivator for 
the peroxisome proliferator-activated receptor $\gamma$," Journal of Biological Chemistry, vol. 274, no. 23, pp. 16147-16152, 1999.

[42] S.-K. Lee, S. L. Anzick, J.-E. Choi et al., "A nuclear factor, ASC-2, as a cancer-amplified transcriptional coactivator essential for ligand-dependent transactivation by nuclear receptors in vivo," Journal of Biological Chemistry, vol. 274, no. 48, pp. 34283-34293, 1999.

[43] K. Jepsen and M. G. Rosenfeld, "Biological roles and mechanistic actions of corepressor complexes," Journal of Cell Science, vol. 115, no. 4, pp. 689-698, 2002.

[44] J. Li, Q. Lin, H.-G. Yoon et al., "Involvement of histone methylation and phosphorylation in regulation of transcription by thyroid hormone receptor," Molecular and Cellular Biology, vol. 22, no. 16, pp. 5688-5697, 2002.

[45] X. Hu, Y. Li, and M. A. Lazar, "Determinants of CoRNRdependent repression complex assembly on nuclear hormone receptors," Molecular and Cellular Biology, vol. 21, no. 5, pp. 1747-1758, 2001.

[46] E. Treuter, T. Albrektsen, L. Johansson, J. Leers, and J.-A. Gustafsson, "A regulatory role for RIP140 in nuclear receptor activation," Molecular Endocrinology, vol. 12, no. 6, pp. 864881, 1998.

[47] G. Pascual, A. L. Fong, S. Ogawa et al., "A SUMOylationdependent pathway mediates transrepression of inflammatory response genes by PPAR- $\gamma$," Nature, vol. 437, no. 7059, pp. 759-763, 2005.

[48] T. Kielian and P. D. Drew, "Effects of peroxisome proliferatoractivated receptor- $\gamma$ agonists on central nervous system inflammation," Journal of Neuroscience Research, vol. 71, no. 3, pp. 315-325, 2003.

[49] S. Hummasti and P. Tontonoz, "The peroxisome proliferatoractivated receptor $\mathrm{N}$-terminal domain controls isotypeselective gene expression and adipogenesis," Molecular Endocrinology, vol. 20, no. 6, pp. 1261-1275, 2006.

[50] A. Werman, A. Hollenberg, G. Solanes, C. Bjørbæk, A. J. Vidal-Puig, and J. S. Flier, "Ligand-independent activation domain in the $\mathrm{N}$ terminus of peroxisome proliferatoractivated receptor $\gamma(\operatorname{PPAR} \gamma)$. Differential activity of PPAR $\gamma 1$ and -2 isoforms and influence of insulin," Journal of Biological Chemistry, vol. 272, no. 32, pp. 20230-20235, 1997.

[51] R. Saladin, L. Fajas, S. Dana, Y.-D. Halvorsen, J. Auwerx, and M. Briggs, "Differential regulation of peroxisome proliferator activated receptor $\gamma 1$ (PPAR $\gamma 1)$ and PPAR $\gamma 2$ messenger RNA expression in the early stages of adipogenesis," Cell Growth and Differentiation, vol. 10, no. 1, pp. 43-48, 1999.

[52] M. Lehrke and M. A. Lazar, "The many faces of PPAR $y$," Cell, vol. 123, no. 6, pp. 993-999, 2005.

[53] Y. Barak, M. C. Nelson, E. S. Ong et al., "PPAR $\gamma$ is required for placental, cardiac, and adipose tissue development," Molecular Cell, vol. 4, no. 4, pp. 585-595, 1999.

[54] J. R. Jones, C. Barrick, K.-A. Kim et al., "Deletion of PPAR $\gamma$ in adipose tissues of mice protects against high fat diet-induced obesity and insulin resistance," Proceedings of the National Academy of Sciences of the United States of America, vol. 102, no. 17, pp. 6207-6212, 2005.

[55] H. Koutnikova, T.-A. Cock, M. Watanabe et al., "Compensation by the muscle limits the metabolic consequences of lipodystrophy in PPAR $y$ hypomorphic mice," Proceedings of the National Academy of Sciences of the United States of America, vol. 100, no. 24, pp. 14457-14462, 2003.

[56] J. Zhang, M. Fu, T. Cui et al., "Selective disruption of PPAR 22 impairs the development of adipose tissue and insulin sensitivity," Proceedings of the National Academy of
Sciences of the United States of America, vol. 101, no. 29, pp. 10703-10708, 2004.

[57] D. Altshuler, J. N. Hirschhorn, M. Klannemark et al., "The common PPAR $\gamma$ Pro12Ala polymorphism is associated with decreased risk of type 2 diabetes," Nature Genetics, vol. 26, no. 1, pp. 76-80, 2000.

[58] G. Medina-Gomez, S. Virtue, C. Lelliott et al., "The link between nutritional status and insulin sensitivity is dependent on the adipocyte-specific peroxisome proliferatoractivated receptor- $\gamma 2$ isoform," Diabetes, vol. 54 , no. 6 , pp. 1706-1716, 2005.

[59] P. D. G. Miles, Y. Barak, W. He, R. M. Evans, and J. M. Olefsky, "Improved insulin-sensitivity in mice heterozygous for PPAR- $\gamma$ deficiency," Journal of Clinical Investigation, vol. 105, no. 3, pp. 287-292, 2000.

[60] P. D. G. Miles, Y. Barak, R. M. Evans, and J. M. Olefsky, "Effect of heterozygous PPAR $y$ deficiency and TZD treatment on insulin resistance associated with age and high-fat feeding," American Journal of Physiology -Endocrinology and Metabolism, vol. 284, no. 3, pp. E618-E626, 2003.

[61] S. I. Anghel, E. Bedu, C. D. Vivier, P. Descombes, B. Desvergne, and W. Wahli, "Adipose tissue integrity as a prerequisite for systemic energy balance: a critical role for peroxisome proliferator-activated receptor $\gamma$," Journal of Biological Chemistry, vol. 282, no. 41, pp. 29946-29957, 2007.

[62] J. Rieusset, J. Seydoux, S. I. Anghel et al., "Altered growth in male peroxisome proliferator-activated receptor $\gamma(\operatorname{PPAR} \gamma)$ heterozygous mice: involvement of PPAR $\gamma$ in a negative feedback regulation of growth hormone action," Molecular Endocrinology, vol. 18, no. 10, pp. 2363-2377, 2004.

[63] W. He, Y. Barak, A. Hevener et al., "Adipose-specific peroxisome proliferator-activated receptor $\gamma$ knockout causes insulin resistance in fat and liver but not in muscle," Proceedings of the National Academy of Sciences of the United States of America, vol. 100, no. 26, pp. 15712-15717, 2003.

[64] M. Hirakata, R. Tozawa, Y. Imura, and Y. Sugiyama, "Comparison of the effects of pioglitazone and rosiglitazone on macrophage foam cell formation," Biochemical and Biophysical Research Communications, vol. 323, no. 3, pp. 782-788, 2004.

[65] P. Tontonoz, L. Nagy, J. G. A. Alvarez, V. A. Thomazy, and R. M. Evans, "PPAR $\gamma$ promotes monocyte/macrophage differentiation and uptake of oxidized LDL," Cell, vol. 93, no. 2, pp. 241-252, 1998.

[66] T. E. Akiyama, S. Sakai, G. Lambert et al., "Conditional disruption of the peroxisome proliferator-activated receptor $\gamma$ gene in mice results in lowered expression of ABCA1, ABCG1, and apoE in macrophages and reduced cholesterol efflux," Molecular and Cellular Biology, vol. 22, no. 8, pp. 2607-2619, 2002.

[67] V. R. Babaev, P. G. Yancey, S. V. Ryzhov et al., "Conditional knockout of macrophage PPAR $\gamma$ increases atherosclerosis in C57BL/6 and low-density lipoprotein receptor-deficient mice," Arteriosclerosis, Thrombosis, and Vascular Biology, vol. 25, no. 8, pp. 1647-1653, 2005.

[68] C. De Luca and J. M. Olefsky, "Stressed out about obesity and insulin resistance," Nature Medicine, vol. 12, no. 1, pp. 41-42, 2006.

[69] S. P. Weisberg, D. McCann, M. Desai, M. Rosenbaum, R. L. Leibel, and A. W. Ferrante Jr., "Obesity is associated with macrophage accumulation in adipose tissue," Journal of Clinical Investigation, vol. 112, no. 12, pp. 1796-1808, 2003.

[70] H. Xu, G. T. Barnes, Q. Yang et al., "Chronic inflammation in fat plays a crucial role in the development of obesity-related 
insulin resistance," Journal of Clinical Investigation, vol. 112, no. 12, pp. 1821-1830, 2003.

[71] S. Heikkinen, J. Auwerx, and C. A. Argmann, "PPAR $\gamma$ in human and mouse physiology," Biochimica et Biophysica Acta, vol. 1771, no. 8, pp. 999-1013, 2007.

[72] W. He, "PPAR $\gamma 2^{\text {Prol2Ala }}$ polymorphism and human health," PPAR Research, vol. 2009, Article ID 849538, 15 pages, 2009.

[73] S. S. Deeb, L. Fajas, M. Nemoto et al., "A Pro12Ala substitution in PPAR $\gamma 2$ associated with decreased receptor activity, lower body mass index and improved insulin sensitivity," Nature Genetics, vol. 20, no. 3, pp. 284-287, 1998.

[74] I. Barroso, M. Gurnell, V. E. F. Crowley et al., "Dominant negative mutations in human PPAR $y$ associated with severe insulin resistance, diabetes mellitus and hypertension," Nature, vol. 402, no. 6764, pp. 880-883, 1999.

[75] J. Masugi, Y. Tamori, H. Mori, T. Koike, and M. Kasuga, "Inhibitory effect of a proline-to-alanine substitution at codon 12 of peroxisome proliferator-activated receptor- $\gamma$ 2 on thiazolidinedione-induced adipogenesis," Biochemical and Biophysical Research Communications, vol. 268, no. 1, pp. 178-182, 2000.

[76] D. B. Savage, M. Agostini, I. Barroso et al., "Digenic inheritance of severe insulin resistance in a human pedigree," Nature Genetics, vol. 31, no. 4, pp. 379-384, 2002.

[77] R. A. Hegele, H. Cao, C. Frankowski, S. T. Mathews, and T. Leff, "PPARG F388L, a transactivation-deficient mutant, in familial partial lipodystrophy," Diabetes, vol. 51, no. 12, pp. 3586-3590, 2002.

[78] M. Kolehmainen, M. I. J. Uusitupa, E. Alhava, M. Laakso, and H. Vidal, "Effect of the Pro12Ala polymorphism in the peroxisome proliferator-activated receptor (PPAR) $\gamma 2$ gene on the expression of PPAR $y$ target genes in adipose tissue of massively obese subjects," Journal of Clinical Endocrinology and Metabolism, vol. 88, no. 4, pp. 1717-1722, 2003.

[79] Y. L. Muller, C. Bogardus, B. A. Beamer, A. R. Shuldiner, and L. J. Baier, "A functional variant in the peroxisome proliferator-activated receptor $\gamma^{2}$ promoter is associated with predictors of obesity and type 2 diabetes in Pima Indians," Diabetes, vol. 52, no. 7, pp. 1864-1871, 2003.

[80] K. Al-Shali, H. Cao, N. Knoers, A. R. Hermus, C. J. Tack, and R. A. Hegele, "A single-base mutation in the peroxisome proliferator-activated receptor $\gamma 4$ promoter associated with altered in vitro expression and partial lipodystrophy," Journal of Clinical Endocrinology and Metabolism, vol. 89, no. 11, pp. 5655-5660, 2004.

[81] M. Agostini, M. Gurnell, D. B. Savage et al., "Tyrosine agonists reverse the molecular defects associated with dominantnegative mutations in human peroxisome proliferatoractivated receptor $\gamma$," Endocrinology, vol. 145, no. 4, pp. 1527 1538, 2004.

[82] M. Agostini, E. Schoenmakers, C. Mitchell et al., "Non-DNA binding, dominant-negative, human PPAR $\gamma$ mutations cause lipodystrophic insulin resistance," Cell Metabolism, vol. 4, no. 4, pp. 303-311, 2006.

[83] S. Heikkinen, C. Argmann, J. N. Feige et al., "The Pro12Ala PPAR $\gamma 2$ variant determines metabolism at the gene-environment interface," Cell Metabolism, vol. 9, no. 1, pp. 88-98, 2009.

[84] D. Capaccio, A. Ciccodicola, L. Sabatino et al., "A novel germline mutation in peroxisome proliferator-activated receptor $\gamma$ gene associated with large intestine polyp formation and dyslipidemia," Biochimica et Biophysica Acta, vol. 1802, no. 6, pp. 572-581, 2010.
[85] H. Mori, H. Ikegami, Y. Kawaguchi et al., "The Pro12 $\rightarrow$ Ala substitution in PPAR- $\gamma$ is associated with resistance to development of diabetes in the general population: possible involvement in impairment of insulin secretion in individuals with type 2 diabetes," Diabetes, vol. 50, no. 4, pp. 891-894, 2001.

[86] S. Masud and S. Ye, "Effect of the peroxisome proliferates activated receptor- $\gamma$ gene Pro12Ala variant on body mass index: a meta-analysis," Journal of Medical Genetics, vol. 40, no. 10, pp. 773-780, 2003.

[87] A. S. F. Doney, B. Fischer, J. E. Cecil et al., "Association of the Pro12Ala and C1431T variants of PPARG and their haplotypes with susceptibility to Type 2 diabetes," Diabetologia, vol. 47, no. 3, pp. 555-558, 2004.

[88] V. Costa, A. Casamassimi, K. Esposito, et al., "Characterization of a novel polymorphism in PPARG regulatory region associated with type 2 diabetes and diabetic retinopathy in Italy," Journal of Biomedicine and Biotechnology, vol. 2009, Article ID 126917, 7 pages, 2009.

[89] D. A. Chistiakov, V. A. Potapov, D. S. Khodirev, M. S. Shamkhalova, M. V. Shestakova, and V. V. Nosikov, "The PPAR $\gamma$ Pro12Ala variant is associated with insulin sensitivity in Russian normoglycaemic and type 2 diabetic subjects," Diabetes and Vascular Disease Research, vol. 7, no. 1, pp. 5662, 2010.

[90] A. Meirhaeghe, L. Fajas, N. Helbecque et al., "A genetic polymorphism of the peroxisome proliferator-activated receptor $\gamma$ gene influences plasma leptin levels in obese humans," Human Molecular Genetics, vol. 7, no. 3, pp. 435-440, 1998.

[91] R. Valve, K. Sivenius, R. Miettinen et al., "Two polymorphisms in the peroxisome proliferator-activated receptor$\gamma$ gene are associated with severe overweight among obese women," Journal of Clinical Endocrinology and Metabolism, vol. 84, no. 10, pp. 3708-3712, 1999.

[92] I. Simón, J. Vendrell, C. Gutiérrez et al., "Pro12Ala substitution in the peroxisome proliferator-activated receptorgamma is associated with increased leptin levels in women with type-2 diabetes mellitus," Hormone Research, vol. 58, no. 3, pp. 143-149, 2002.

[93] J. Schneider, J. Kreuzer, A. Hamann, P. P. Nawroth, and K. A. Dugi, "The proline 12 alanine substitution in the peroxisome proliferator-activated receptor- $\gamma 2$ gene is associated with lower lipoprotein lipase activity in vivo," Diabetes, vol. 51, no. 3, pp. 867-870, 2002.

[94] Y. Yamamoto, H. Hirose, K. Miyashita et al., "PPAR 22 gene Pro12Ala polymorphism may influence serum level of an adipocyte-derived protein, adiponectin, in the Japanese population," Metabolism, vol. 51, no. 11, pp. 1407-1409, 2002.

[95] A. Meirhaeghe, L. Fajas, F. Gouilleux et al., "A functional polymorphism in a STAT5B site of the human PPAR $\gamma 3$ gene promoter affects height and lipid metabolism in a French population," Arteriosclerosis, Thrombosis, and Vascular Biology, vol. 23, no. 2, pp. 289-294, 2003.

[96] N. Takata, T. Awata, K. Inukai et al., "Pro12Ala substitution in peroxisome proliferator-activated receptor $\gamma 2$ is associated with low adiponectin concentrations in young Japanese men," Metabolism, vol. 53, no. 12, pp. 1548-1551, 2004.

[97] C. Wang, F. Zhai, Y. Chi, and G. Wang, "Association of Pro12Ala mutation in peroxisome proliferator-activated receptor gamma 2 with obesity and diabetes in Chinese population," Wei Sheng Yan Jiu, vol. 33, no. 3, pp. 317-320, 2004. 
[98] F. Orio Jr., S. Palomba, T. Cascella et al., "Lack of an association between peroxisome proliferator-activated receptor- $\gamma$ gene Pro12Ala polymorphism and adiponectin levels in the polycystic ovary syndrome," Journal of Clinical Endocrinology and Metabolism, vol. 89, no. 10, pp. 5110-5115, 2004.

[99] A. Meirhaeghe, D. Cottel, P. Amouyel, and J. Dallongeville, "Association between peroxisome proliferatoractivated receptor $\gamma$ haplotypes and the metabolic syndrome in French men and women," Diabetes, vol. 54, no. 10, pp. 3043-3048, 2005.

[100] B. Bidzińska-Speichert, M. Demissie, U. Tworowska et al., "Leptin level and the PPARgamma2 Pro12Ala and Pro115Gln polymorphisms in women with functional hyperandrogenism. Preliminary report," Przeglad Lekarski, vol. 62, no. 9, pp. 833-837, 2005.

[101] V. Radha, K. S. Vimaleswaran, S. Babu et al., "Lack of association between serum adiponectin levels and the Pro12Ala polymorphism in Asian Indians," Diabetic Medicine, vol. 24, no. 4, pp. 398-402, 2007.

[102] A. Haseeb, M. Iliyas, S. Chakrabarti et al., "Single-nucleotide polymorphisms in peroxisome proliferator-activated receptor gamma and their association with plasma levels of resistin and the metabolic syndrome in a South Indian population," Journal of Biosciences, vol. 34, no. 3, pp. 405-414, 2009.

[103] A. S. F. Doney, B. Fischer, G. Leese, A. D. Morris, and C. N. A. Palmer, "Cardiovascular risk in type 2 diabetes is associated with variation at the PPARG locus: a go-DARTS study," Arteriosclerosis, Thrombosis, and Vascular Biology, vol. 24, no. 12, pp. 2403-2407, 2004.

[104] F. P. Mancini, O. Vaccaro, L. Sabatino et al., "Pro12Ala substitution in the peroxisome proliferator-activated receptor- $\gamma 2$ is not associated with type 2 diabetes," Diabetes, vol. 48 , no. 7, pp. 1466-1468, 1999.

[105] D. K. Sanghera, F. Y. Demirci, L. Been et al., "PPARG and ADIPOQ gene polymorphisms increase type 2 diabetes mellitus risk in Asian Indian Sikhs: Pro12Ala still remains as the strongest predictor," Metabolism, vol. 59, no. 4, pp. 492$501,2010$.

[106] E. J. Rhee, K. W. Oh, W. Y. Lee et al., "Effects of two common polymorphisms of peroxisome proliferator-activated receptor- $\gamma$ gene on metabolic syndrome," Archives of Medical Research, vol. 37, no. 1, pp. 86-94, 2006.

[107] E. S. Tai, D. Corella, M. Deurenberg-Yap et al., "Differential effects of the C1431T and Pro12Ala PPAR $y$ gene variants on plasma lipids and diabetes risk in an Asian population," Journal of Lipid Research, vol. 45, no. 4, pp. 674-685, 2004.

[108] M. Ristow, D. Müller-Wieland, A. Pfeiffer, W. Krone, and C. R. Kahn, "Obesity associated with a mutation in a genetic regulator of adipocyte differentiation," New England Journal of Medicine, vol. 339, no. 14, pp. 953-959, 1998.

[109] A. K. Agarwal and A. Garg, "A novel heterozygous mutation in peroxisome proliferator-activated receptor- $\gamma$ gene in a patient with familial partial lipodystrophy," Journal of Clinical Endocrinology and Metabolism, vol. 87, no. 1, pp. 408-411, 2002.

[110] H. N. Gouda, G. S. Sagoo, A.-H. Harding, J. Yates, M. S. Sandhu, and J. P. T. Higgins, "The association between the peroxisome proliferator-activated receptor- $\gamma 2$ (PPARG2) Pro12Ala gene variant and type 2 diabetes mellitus: a HuGE review and meta-analysis," American Journal of Epidemiology, vol. 171, no. 6, pp. 645-655, 2010.

[111] T.-Y. Zheng, Y.-J. Lin, and J.-C. Horng, "Thermodynamic consequences of incorporating 4-substituted proline derivatives into a small helical protein," Biochemistry, vol. 49, no. 19, pp. 4255-4263, 2010.

[112] K. Clement, S. Hercberg, B. Passinge et al., "The Pro115Gln and Pro12Ala PPAR gamma gene mutations in obesity and type 2 diabetes," International Journal of Obesity, vol. 24, no. 3, pp. 391-393, 2000.

[113] T. T. Agústsson, H. Hákonarson, I. Olafsson, G. Hjaltadóttir, and A. V. Thornórsson, "A mutation detection in a transcription factor for adipocyte development in children with severe obesity," Laeknabladid, vol. 87, no. 2, pp. 119-124, 2001.

[114] O. W. Hamer, D. Forstner, I. Ottinger et al., "The pro115Gln polymorphism within the PPAR $\gamma 2$ gene has no epidemiological impact on morbid obesity," Experimental and Clinical Endocrinology and Diabetes, vol. 110, no. 5, pp. 230-234, 2002.

[115] M. B. Hadj Mohamed, N. Mtiraoui, I. Ezzidi, M. Chaieb, T. Mahjoub, and W. Y. Almawi, "Association of the peroxisome proliferator-activated receptor- $\gamma 2$ Pro12Ala but not the C1431T gene variants with lower body mass index in type 2 diabetes," Journal of Endocrinological Investigation, vol. 30, no. 11, pp. 937-943, 2007.

[116] M. Stumvoll and H. Häring, "The peroxisome proliferatoractivated receptor- $\gamma 2$ Pro12Ala polymorphism," Diabetes, vol. 51, no. 8, pp. 2341-2347, 2002.

[117] T. I. Lee and R. A. Young, "Transcription of eukaryotic protein-coding genes," Annual Review of Genetics, vol. 34, pp. 77-137, 2000.

[118] G. Jimenez-Sanchez, B. Childs, and D. Valle, "Human disease genes," Nature, vol. 409, no. 6822, pp. 853-855, 2001.

[119] E. R. Mardis, "Next-generation DNA sequencing methods," Annual Review of Genomics and Human Genetics, vol. 9, pp. 387-402, 2008.

[120] J. M. Vaquerizas, S. K. Kummerfeld, S. A. Teichmann, and N. M. Luscombe, "A census of human transcription factors: function, expression and evolution," Nature Reviews Genetics, vol. 10, no. 4, pp. 252-263, 2009.

[121] V. Costa, C. Angelini, I. de Feis, and A. Ciccodicola, "Uncovering the complexity of transcriptomes with RNASeq," Journal of Biomedicine and Biotechnology, vol. 2010, Article ID 853916, 19 pages, 2010.

[122] M. L. Metzker, "Sequencing technologies—-the next generation," Nature Reviews Genetics, vol. 11, no. 1, pp. 31-46, 2010.

[123] G. Robertson, M. Hirst, M. Bainbridge et al., "Genomewide profiles of STAT1 DNA association using chromatin immunoprecipitation and massively parallel sequencing," Nature Methods, vol. 4, no. 8, pp. 651-657, 2007.

[124] A. Valouev, D. S. Johnson, A. Sundquist et al., "Genome-wide analysis of transcription factor binding sites based on ChIPSeq data," Nature Methods, vol. 5, no. 9, pp. 829-834, 2008.

[125] T. E. Reddy, F. Pauli, R. O. Sprouse et al., "Genomic determination of the glucocorticoid response reveals unexpected mechanisms of gene regulation," Genome Research, vol. 19, no. 12, pp. 2163-2171, 2009.

[126] F. Dahl, M. Gullberg, J. Stenberg, U. Landegren, and M. Nilsson, "Multiplex amplification enabled by selective circularization of large sets of genomic DNA fragments," Nucleic Acids Research, vol. 33, no. 8, article e71, 2005.

[127] S. Fredriksson, J. Banér, F. Dahl et al., "Multiplex amplification of all coding sequences within 10 cancer genes by GeneCollector," Nucleic Acids Research, vol. 35, no. 7, article e47, 2007.

[128] G. J. Porreca, K. Zhang, J. B. Li et al., "Multiplex amplification of large sets of human exons," Nature Methods, vol. 4, no. 11, pp. 931-936, 2007. 
[129] J. Shendure and H. Ji, "Next-generation DNA sequencing," Nature Biotechnology, vol. 26, no. 10, pp. 1135-1145, 2008.

[130] E. Hodges, Z. Xuan, V. Balija et al., "Genome-wide in situ exon capture for selective resequencing," Nature Genetics, vol. 39, no. 12, pp. 1522-1527, 2007.

[131] T. J. Albert, M. N. Molla, D. M. Muzny et al., "Direct selection of human genomic loci by microarray hybridization," Nature Methods, vol. 4, no. 11, pp. 903-905, 2007.

[132] L.-S. Chou, C.-S. J. Liu, B. Boese, X. Zhang, and R. Mao, "DNA sequence capture and enrichment by microarray followed by next-generation sequencing for targeted resequencing: neurofibromatosis type 1 gene as a model," Clinical Chemistry, vol. 56, no. 1, pp. 62-72, 2010.

[133] G. A. Heap, J. H. M. Yang, K. Downes et al., "Genomewide analysis of allelic expression imbalance in human primary cells by high-throughput transcriptome resequencing," Human Molecular Genetics, vol. 19, no. 1, pp. 122-134, 2010.

[134] D. J. Sugarbaker, W. G. Richards, G. J. Gordon et al., "Transcriptome sequencing of malignant pleural mesothelioma tumors," Proceedings of the National Academy of Sciences of the United States of America, vol. 105, no. 9, pp. 3521-3526, 2008.

[135] A. M. Barrio, O. Eriksson, J. Badhai et al., "Targeted resequencing and analysis of the diamond-blackfan anemia disease locus RPS19," PLoS ONE, vol. 4, no. 7, article e6172, 2009.

[136] P. J. Park, "ChIP-seq: advantages and challenges of a maturing technology," Nature Reviews Genetics, vol. 10, no. 10, pp. 669680, 2009.

[137] V. E. Velculescu, L. Zhang, W. Zhou et al., "Characterization of the yeast transcriptome," Cell, vol. 88, no. 2, pp. 243-251, 1997.

[138] E. Birney, J. A. Stamatoyannopoulos, A. Dutta et al., "Identification and analysis of functional elements in $1 \%$ of the human genome by the ENCODE pilot project," Nature, vol. 447, no. 7146, pp. 799-816, 2007.

[139] A. Jacquier, "The complex eukaryotic transcriptome: unexpected pervasive transcription and novel small RNAs," Nature Reviews Genetics, vol. 10, no. 12, pp. 833-844, 2009.

[140] N. Cloonan, A. R. R. Forrest, G. Kolle et al., "Stem cell transcriptome profiling via massive-scale mRNA sequencing," Nature Methods, vol. 5, no. 7, pp. 613-619, 2008.

[141] J. C. Marioni, C. E. Mason, S. M. Mane, M. Stephens, and Y. Gilad, "RNA-Seq: an assessment of technical reproducibility and comparison with gene expression arrays," Genome Research, vol. 18, no. 9, pp. 1509-1517, 2008.

[142] A. Mortazavi, B. A. Williams, K. McCue, L. Schaeffer, and B. Wold, "Mapping and quantifying mammalian transcriptomes by RNA-Seq," Nature Methods, vol. 5, no. 7, pp. 621628, 2008.

[143] U. Nagalakshmi, Z. Wang, K. Waern et al., "The transcriptional landscape of the yeast genome defined by RNA sequencing," Science, vol. 320, no. 5881, pp. 1344-1349, 2008.

[144] T. T. Torres, M. Metta, B. Ottenwälder, and C. Schlötterer, "Gene expression profiling by massively parallel sequencing," Genome Research, vol. 18, no. 1, pp. 172-177, 2008.

[145] M. Sultan, M. H. Schulz, H. Richard et al., "A global view of gene activity and alternative splicing by deep sequencing of the human transcriptome," Science, vol. 321, no. 5891, pp. 956-960, 2008.

[146] S.-I. Hashimoto, W. Qu, B. Ahsan et al., "High-resolution analysis of the $5^{\prime}$-end transcriptome using a next generation DNA sequencer," PLoS ONE, vol. 4, no. 1, article e4108, 2009.
[147] F. Tang, C. Barbacioru, Y. Wang et al., "mRNA-Seq wholetranscriptome analysis of a single cell," Nature Methods, vol. 6, no. 5, pp. 377-382, 2009.

[148] Z. Wang, M. Gerstein, and M. Snyder, "RNA-Seq: a revolutionary tool for transcriptomics," Nature Reviews Genetics, vol. 10, no. 1, pp. 57-63, 2009.

[149] B. T. Wilhelm, S. Marguerat, I. Goodhead, and J. Bähler, "Defining transcribed regions using RNA-Seq," Nature Protocols, vol. 5, no. 2, pp. 255-266, 2010. 


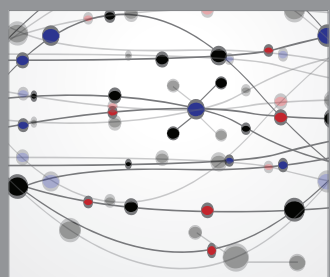

The Scientific World Journal
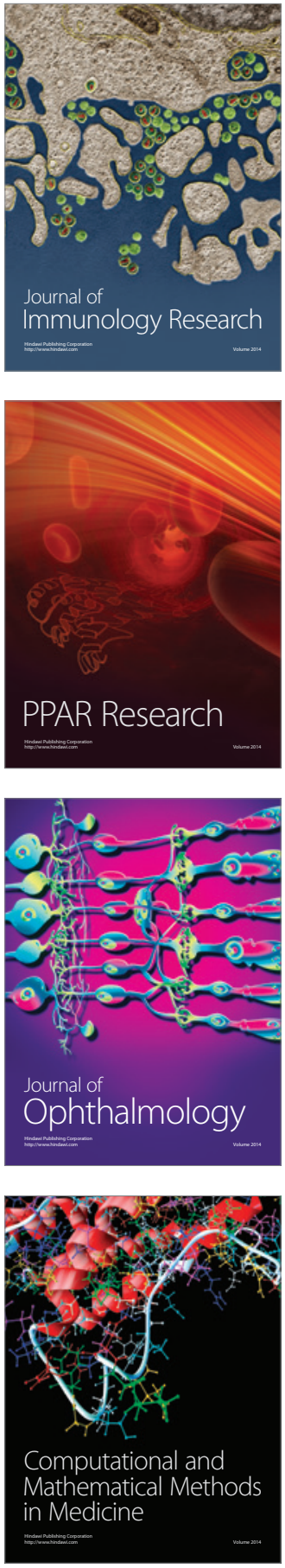

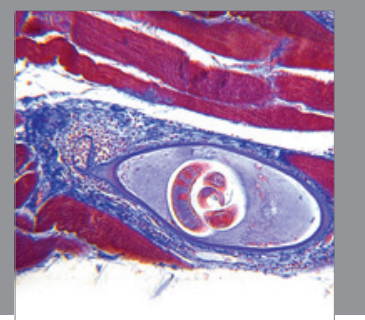

Gastroenterology

Research and Practice
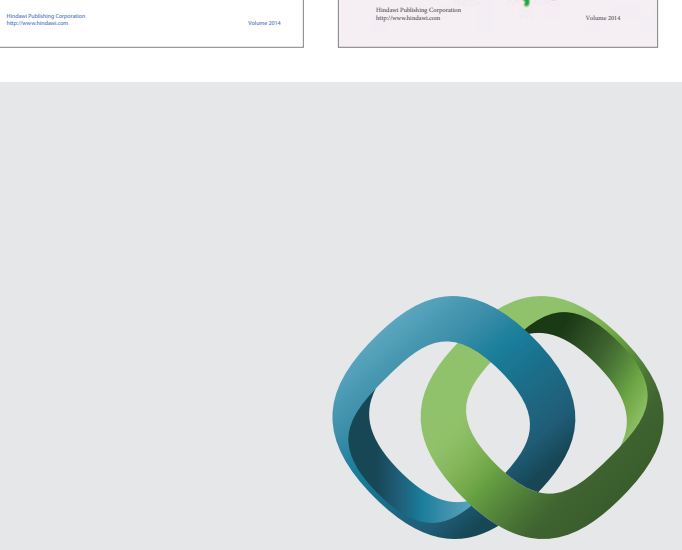

\section{Hindawi}

Submit your manuscripts at

http://www.hindawi.com
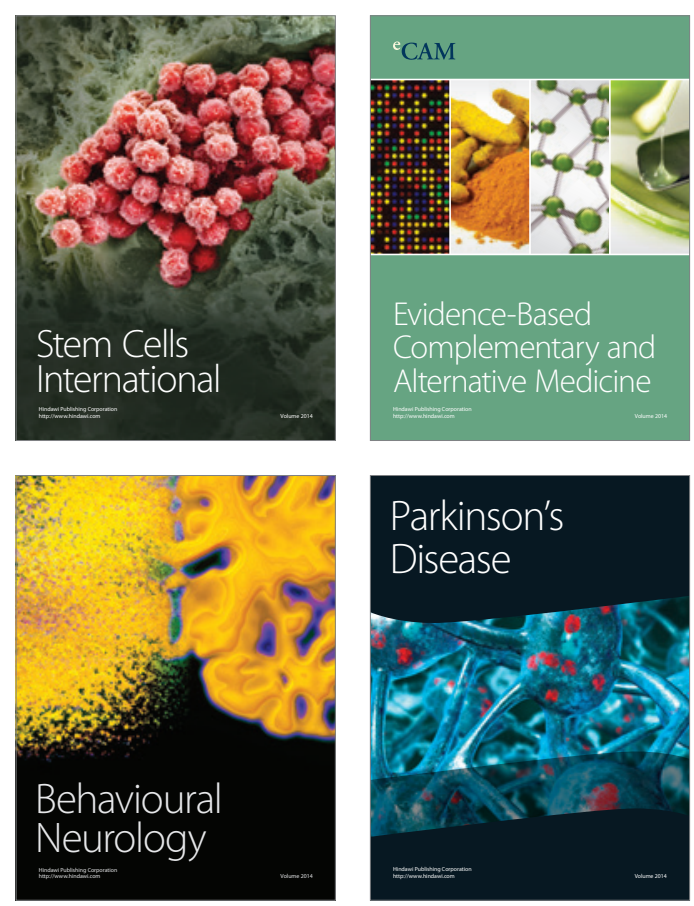

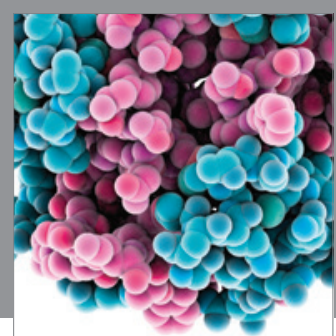

Journal of
Diabetes Research

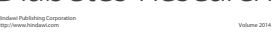

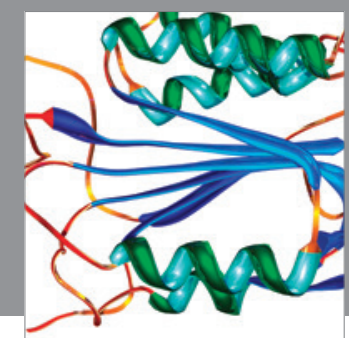

Disease Markers
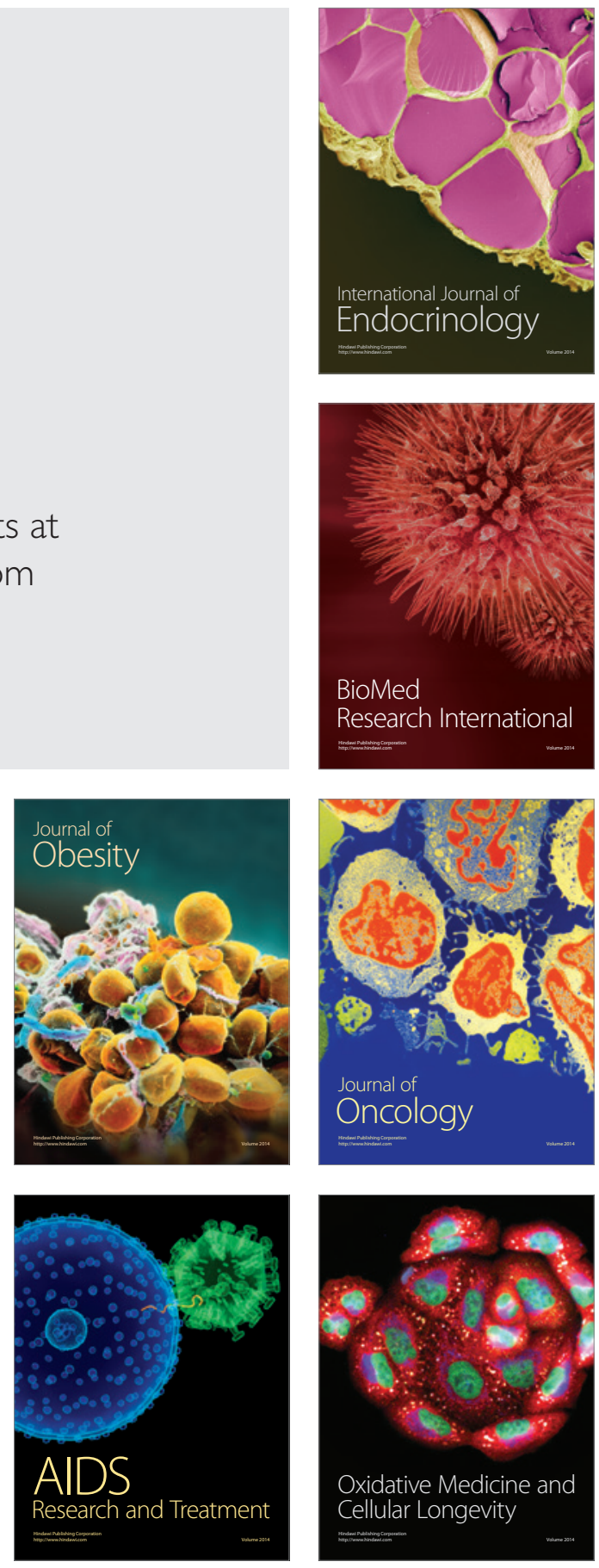